\title{
Towards Definition of the Risk Premium Function
}

\author{
Nikola Krečar M IEEE, Fred E. Benth, Andrej F. Gubina, SM IEEE
}

\begin{abstract}
Successful trading in electricity markets relies on the market actor's ability to accurately forecast the electricity price. The fundamental electricity price models use market information, provided by various price drivers, including the residual that contains a risk premium. In the past, researchers investigating risk premium focused primarily on daily spot price levels, ignoring the intraday information hindering the accurate risk premium determination. This paper presents a new KGB Method for modelling of risk premium, based on "ex-ante" approach focused on a yearly product. The method involves a novel KGB Model and its linearized formulation, the KGB Linear Model, which enables capturing the influence of renewable energy sources on risk premium. The four key drivers of the KGB Linear Model were used providing an insight into the influence of RES generation on risk premium evolution. The method was tested on historical data from the German electricity market. The results for the 2010 - 2014 period reveal overall influence of PV production share on risk premium is greater than that of wind production share, both increasing the risk premium due to their variability and uncertainty. Using the KGB Method, market actors can forecast risk premium using information readily available to them.
\end{abstract}

Key words-risk premium, PV production, wind production, RES production, risk premium model, electricity price, fundamental electricity price models, electricity markets.

\section{INTRODUCTION}

$\mathrm{F}$ ORECASTING of electricity price is one of the key support tools for companies trading in the wholesale electricity market, so the choice of an appropriate forecasting model is of great importance to them, [1]. Market actors calibrate their forecasting models corresponding to their vision of the market as well as their trading strategy.

N. Krečar is with the Faculty of Electrical Engineering, University of Ljubljana, Slovenia (e-mail: nikola@krecar.eu).

F. E. Benth is with the University of Oslo, Norway. (e-mail: fredb@math.uio.no).

A. F. Gubina is with the Faculty of Electrical Engineering, University of Ljubljana, Slovenia (e-mail: andrej.gubina@fe.uni-lj.si)

Manuscript received December 11, 2018. The authors acknowledge the financial support from the Slovenian Research Agency (research core funding No. P2-0356).
According to their market roles, they follow different trading strategies, exhibiting various levels of risk tolerance.

Among the actors, traders primarily realize a profit from taking on the risk on the electricity market. They do this by opening a trading position based on their view of the market and on their risk tolerance level. In contrast, the producers and the large- or the mid-scale suppliers are primarily responding to relative price levels on the market and are typically less interested in quantifying the risk levels of their trades.

In an ideal electricity market, the expected spot price of electricity as forecasted by the model would equal the actual traded derivative future price. However, the expected spot price does not perfectly conform to the price of the traded futures even with frequent updates of the forecast, and the difference appears to be stochastic. We could therefore assume that this difference does not contain only a forecast error, but also a specific quantity - a Risk Premium (RP), [2].

$\mathrm{RP}$ is a part of the future commodity price that comprises the expected future risk and the expected spot price. A producer is willing to sell its future production at the expected future commodity price, and the consumer is prepared to pay RP within the expected future commodity price to eliminate the future price risk, [3]. In the literature, various RP definitions can be found. While some authors, [4], deal with a general notion of RP, others classify RP into several types, based on:

- The used calculation approach, e.g. "ex-ante” or "expost”, [2], [5], [6], or

- The assessed risk type, e.g. "statistical risk", "fundamental risk" and "behavioral risk", respectively, [5].

In the "ex-post” RP calculation approach, RP is defined as a difference between the traded futures price and the realized spot price, [7]-[9]. However, this assumption would hold only if the electricity price was stationary in the delivery time horizon (t, T). Since the price is generally not stationary over time, [10], that difference contains also a forecast error in addition to RP, [5]. Consequently, we believe that the "expost” approach yields incorrect RP results since it ignores the forecast error.

The "ex-ante" RP calculation approach, Fig. 1, has a different philosophy. The traded futures price is considered at the time of the expected spot price forecast. Therefore, all market data used to compute RP are captured at the same time. Since the "ex-ante" approach does not assume the 
electricity price as stationary, it allows for a correct calculation of RP.

Researchers acknowledge that "ex-ante" approach is highly dependent on the subjective choice of a forecasting model for the expected spot price determination, [1].

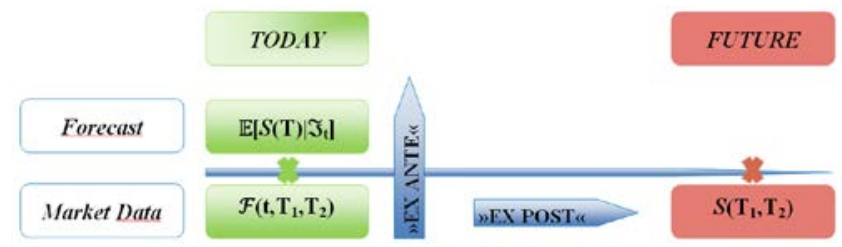

Fig. 1. The "ex-post” and "ex-ante” RP calculation approaches compared

The dynamic behavior of RP is also influenced by energy storage. The latest findings show a strong inverse correlation of RP with water reservoir levels, [2], [11]. Namely, the electricity stored in a full water reservoir can be injected during the times of energy shortage on the market, reducing the potential price spikes. Since the market actors expect that kind of hydro power producer behavior, the full water reservoir levels reduce the future price uncertainty on the market, as expressed with RP. Furthermore, the authors state that this correlation can be extrapolated to all energy storage technologies, [2], [11]. They also suggest a possible dependence of RP on the variable and uncertain electricity production from Renewable Energy Sources (RES) production, in particular wind- and solar photovoltaic (PV) production. However, we are not aware of any current research focusing on modeling of that dependence.

The research of RP in the energy markets came to focus in the past decade, with several authors stating that RP is timevarying, [2], [6]. While the formulation of the behavior of RP in the literature is diverse, they all define it as a component of the forecasted price that increases or decreases the expected price due to uncertainty inherent in the »ex-ante« approach, [1].

Most of the "ex-ante" RP research focuses on forecasting of RP in short-term spot market (day- to week ahead). Some claim that strong positive RP occurs due to tightness of the system, attributing the cause to fundamental factors such as power plant availability, wind power production and demand, [12]. On a short-term time horizon (up to 1 month), "ex-ante" modelling can result in highly positive RP for base load products [7], [12], [13]. Yet, [5], Bunn's findings on the shortterm day-ahead market show RP for peak being positive where off-peak is on average negative. In the same study considering month-ahead RP results show that peak and offpeak products during the winter carry positive RP, and during the summer the results of peak and off-peak RP are negative. Still, in [6], within the "ex-ante" short-term monthly RP research, the authors claim that the average RP increases with the length of the time-to-maturity, considering RP in general positive for the long-term yearly products. For the long term horizon up to two years ahead, some authors, [9], examine the forward RP in the net hedging demand of market actors. They develop a model that yields decreasing absolute values of forward RP (eventually getting negative) when time-tomaturity or delivery period length increases, [5].

The focus of the present paper is on the longer-term horizon (yearly products), as exhibited in the traded futures products with an additional focus on peak/off-peak dynamics through peak and off-peak periods. This is a less-researched area, yet of high interest of the market actors. Therefore, we have proposed a robust model that does not respond to quick changes in trends present in the input data that are typical in day-ahead markets. Such a model is well suited for forecasting of RP in long-term products, but not so much for $\mathrm{RP}$ forecasting in the short-term products.

In the last 5 years we witness a steep growth of variable RES, most notably PV and wind generation that introduced increased generation uncertainty, intuitively increasing the long-term RP. This trend is likely to continue in the following decade, [14], [15], so the trend of increased RP is likely to persist.

In the paper, a new method for RP determination is presented. The KGB (Krečar-Gubina-Benth) Method is based on the "ex-ante" approach that allows for mathematical calculation of RP. The method involves a novel KGB Model and its alternative formulation, the KGB Linear Model that enables capturing the influence of RES drivers on RP. The KGB Method envisions calibration of the KGB Linear Model using the multiple linear regression (MLR). The key drivers used in the KGB Linear Model are determined through correlation with the calculated RP values. By correlating RP with the PV production and wind production time series, we provide an insight into how the RES generation units influence RP evolution and consequently the electricity price on the market.

\section{ANALytical KGB Risk PREMiUm Model}

In the »ex-ante« RP modeling approach, [5], the difference between the current futures price $\mathcal{F}(t, T)$ and expected spot price $\mathbb{E}\left[S(T) \mid \mathfrak{I}_{t}\right]$ for a future time $T$ can be expressed as $\Delta(t$, T) (1).

$$
\mathcal{F}(t, T)-\mathbb{E}\left[S(T) \mid \widetilde{I}_{t}\right]=\Delta(t, T)
$$

We can assume that the spot price is observed in a filtration $\mathfrak{J}_{t}$, containing all market information up to time $t . \Delta(t, T)$ is a sum of RP $R(t, T)$, forecast error $\varepsilon$ and random noise $\vartheta_{t}$, (2),

$$
\Delta(t, T)=R(t, T)+\varepsilon+\vartheta_{t}
$$

The forecast error $\varepsilon$ is mainly related to the expected deviation between the results of an ideal forecast and the individual actors' forecasts. Since we propose a general forecasting method, this component can be assumed to be on average close to zero, $\varepsilon=0$, and therefore it is considered for simplicity to be equal to zero from now on. Random noise $\vartheta_{t}$ describes the market movements due to the activity of the relevant market actors. Since an ideal market is liquid enough to neutralize these effects, the model has been designed for the ideal market without random noise $\vartheta_{t}=0$. Hence, under the 
ideal conditions, It is assumed that $\Delta(t, T)$ comprises only RP, s.t. $\Delta(t, T)=R(t, T)$. Equation (1) becomes (3),

$$
\mathcal{F}(t, T)-\mathbb{E}\left[S(T) \mid \mathfrak{I}_{t}\right]=R(t, T)
$$

By definition, RP is calculated as the difference between the future value of delivered electricity price $\mathcal{F}(t, T)$ and the estimated value of its spot price $\mathbb{E}\left[S(T) \mid \Im_{t}\right]$ at time $t$ for the future delivery period interval $\left[T_{1}, T_{2}\right]$. The generalized expression of RP can be written as (4).

$$
R\left(t, T_{1}, T_{2}\right)=\mathcal{F}\left(t, T_{1}, T_{2}\right)-\frac{1}{T_{2}-T_{1}} \int_{T_{1}}^{T_{2}} \mathbb{E}\left[S(T) \mid \Im_{t}\right] d T
$$

Here $R\left(t, T_{1}, T_{2}\right)$ represents $\mathrm{RP}$, and the futures price is represented as $\mathcal{F}\left(t, T_{1}, T_{2}\right)$ at time $t$ for the delivery time period $\left[T_{1}, T_{2}\right]$. The spot price $S(T)$ can be defined as a sum of deterministic $\Lambda(T)$ and stochastic $X(T)$ components, to model each process independently in (5), [16].

$$
S(T)=\Lambda(T)+X(T)
$$

The deterministic component $\Lambda(T)$ at time $T$ can be modeled explicitly as a seasonally varying mean. In order to express the dynamics of $X(T)$ we use an Ornstein-Uhlenbeck (OU) process driven by a Brownian motion $B(t)$.

$$
d X(t)=-\alpha X(t) d t+\sigma d B(t)
$$

Here $\alpha$ represents the speed of mean reversion and $\sigma$ is the volatility. An OU-process is mean-reverting, meaning that prices deviating from the long-term mean $\Lambda(t)$ will tend to return to it. The farther the prices are away from the mean, the stronger mean reversion is. This is in line with economic reasoning, e.g. very high prices will lead to reduced demand, and in turn to reduction in prices. The expected value of the stochastic process $X(T)$ is expressed as a sum of two parts, (7),

$$
\begin{aligned}
& \mathbb{E}\left[X(T) \mid \Im_{t}\right]=\mathbb{E}\left[X(t) e^{-\alpha(T-t)}\right. \\
& \left.\quad+\sigma \int_{t}^{T} e^{-\alpha(T-s)} d B(s) \mid \Im_{t}\right]
\end{aligned}
$$

Since the stochastic integral inside the conditional expectation of (7) has zero mean and is independent of the $\sigma-\mathfrak{J}_{t}$, its estimated value equals zero as well, (8).

$$
\mathbb{E}\left[\sigma \int_{t}^{T} e^{-\alpha(T-s)} d B(s) \mid \mathfrak{I}_{t}\right]=0
$$

The expected spot price for the period $\left[T_{1}, T_{2}\right]$ equals to deviation of spot price and deterministic component multiplied by exponential expression, (9),

$$
\begin{gathered}
\mathbb{E}\left[X(T) \mid \mathfrak{I}_{t}\right]=X(t) e^{-\alpha(T-t)}+0 \\
\mathbb{E}\left[X(T) \mid \Im_{t}\right]=[\underbrace{S(t)-\Lambda(t)}_{X(t)}] e^{-\alpha(T-t)}
\end{gathered}
$$
(11).

expression (10) is inserted into (4) and (5) to express RP,

$$
R\left(t, T_{1}, T_{2}\right)=\mathcal{F}\left(t, T_{1}, T_{2}\right)
$$

$-\underbrace{\frac{1}{T_{2}-T_{1}} \int_{T_{1}}^{T_{2}}\left\{\Lambda(T)+[S(t)-\Lambda(t)] e^{-\alpha(T-t)}\right\} d T}_{I}$

Introducing $I$ as a substituting variable leads to (12).

$$
\begin{gathered}
I=\frac{1}{T_{2}-T_{1}} \int_{T_{1}}^{T_{2}} \Lambda(T) d T+\frac{1}{T_{2}-T_{1}} \int_{T_{1}}^{T_{2}} S(t) e^{-\alpha(T-t)} d T \\
-\frac{1}{T_{2}-T_{1}} \int_{T_{1}}^{T_{2}} \Lambda(t) e^{-\alpha(T-t)} d T
\end{gathered}
$$

By integration, (12) becomes (13).

$$
I=\bar{\Lambda}\left(T_{1}, T_{2}\right)+[S(t)-\Lambda(t)] \frac{1}{T_{2}-T_{1}} \int_{T_{1}}^{T_{2}} e^{-\alpha(T-t)} d T(13)
$$

Additionally, the integral in (13) is solved as in (14).

$$
\begin{gathered}
\int_{T_{1}}^{T_{2}} e^{-(T-t)} d T \stackrel{\Delta}{\rightarrow} \\
\stackrel{\Delta}{\rightarrow}\left\{\begin{array}{c}
-\frac{1}{T_{2}-T_{1}} e^{\alpha t} \frac{\left(e^{-\alpha T_{2}}-e^{-\alpha T_{1}}\right)}{\alpha} \\
\alpha=0
\end{array}\right.
\end{gathered}
$$

Hence, $I$ can be expressed as (15).

$$
\begin{gathered}
I=\bar{\Lambda}\left(T_{1}, T_{2}\right) \\
+[S(t)-\Lambda(t)] \underbrace{\frac{1}{T_{2}-T_{1}} e^{\alpha t} \frac{\left(e^{-\alpha T_{2}}-e^{-\alpha T_{1}}\right)}{-\alpha}}_{\Omega\left(t, T_{1}, T_{2}\right)}
\end{gathered}
$$

Consequently, the KGB Model expresses RP as (16).

$$
R\left(t, T_{1}, T_{2}\right)=\mathcal{F}\left(t, T_{1}, T_{2}\right)-I
$$

From (15), $\Omega$ is expressed as (17),

$$
\Omega\left(t, T_{1}, T_{2}\right)=\left\{\begin{array}{c}
t \leq T_{1} ; \frac{1}{T_{2}-T_{1}} e^{\alpha t} \frac{\left(e^{-\alpha T_{2}}-e^{-\alpha T_{1}}\right)}{-\alpha} \\
t>T_{1} ;
\end{array}\right.
$$

\section{DEFinition OF KGB Linear Model}

Among the most important characteristics of the electricity spot price are its volatility and mean reversion, [17]. To incorporate these characteristics, the Schwartz model [18] and [19] has been chosen as a classic price model for commodity markets. The Schwartz model extends the Brownian motion model by allowing for mean reversion, (6). It contains a seasonality component and an OU process. To find the forward price under a pricing measure $Q$ equivalent to $P$, Brownian motion is expressed as a combination of a Wiener process and a drift in (18).

$$
d B(t)=d W(t)+\frac{1}{\sigma} \mu(\vec{Z}(t)) d t
$$

A measure change is expressed in (18) and (19), linking $Q$ with an adapted $R^{n}$-valued stochastic process $\vec{Z}$ and a measurable function $\mu$. If the Radon-Nikodym density $d Q / d P$ expressed in (19)

$$
t \mapsto \exp \left(\int_{0}^{t} \mu(\vec{Z}(s) d B(s))-\frac{1}{2} \int_{0}^{t} \mu^{2}(\vec{Z}(s)) d s\right)
$$


is a true martingale, Girsanov's Theorem [20]-[22] ensures the existence of an equivalent probability $Q \sim P$ such that $W$ is a Q-Brownian motion on a finite time interval. A true martingale ensures that the expected value is one, hence defining a probability measure. In general, (19) is only a local martingale if $\mu(\vec{Z}(s))$ is an Ito integrable process. For the moment, we suppose that $\mu$ and $\vec{Z}(s)$ satisfy additional conditions that yield the martingale property of (19). This way the Q-dynamics of $X$ becomes, (20):

$$
d X(t)=[\mu(\vec{Z}(t))-\alpha X(t)] d t+\sigma d W(t)
$$

Or, on the explicit form, $X(T)$ is expressed as in (21).

$$
\begin{aligned}
& X(T)=e^{-\alpha(T-t)} X(\mathrm{t}) \\
& +\sigma \int_{\mathrm{t}}^{T} e^{-\alpha(T-s)} d W(s) \\
& +\int_{\mathrm{t}}^{T} e^{-\alpha(T-s)} \mu(\vec{Z}(s)) d s
\end{aligned}
$$

Hence, the forward price (for a fixed-delivery contract) can be easily expressed as in (22).

$$
\begin{gathered}
\mathcal{F}(t, T)=\mathbb{E}_{Q}\left[S(T) \mid \mathfrak{I}_{t}\right] \\
=\Lambda(T)+e^{-\alpha(T-t)} \underbrace{X(\mathrm{t})}_{S(\mathrm{t})-\Lambda(\mathrm{t})} \\
+\underbrace{\left.\int_{\mathrm{t}}^{T} e^{-\alpha(T-s)} \mathbb{E}_{Q}\left[\mu(\vec{Z}(s)) \mid \widetilde{J}_{t}\right)\right] d s}_{\text {proposed linearisation }}
\end{gathered}
$$

The Wiener process has independent increments with zero mean, yielding the expression for the risk premium as in (23),

$$
\begin{aligned}
& R(t, T)=\mathcal{F}(t, T)-\mathbb{E}\left[S(T) \mid \mathfrak{I}_{t}\right] \\
& =\int_{t}^{T} e^{-\alpha(T-s)} \mathbb{E}_{Q}\left[\mu(\vec{Z}(s)) \mid \mathfrak{I}_{t}\right] d s
\end{aligned}
$$

We assume that $\mu$ is such that the conditional expectation under $Q$ can be expressed in (24) by a linear combination of the factors in $\vec{Z}(t)$ for deterministic functions $a_{1}, . . a_{n}$.

$$
\begin{aligned}
& \quad \mathbb{E}_{Q}\left[\mu(\vec{Z}(s)) \mid \widetilde{I}_{t}\right]=\vec{a}^{T}(t, s) \vec{Z}(t)=a_{1}(t, s) Z_{1}(t) \\
& +a_{2}(t, s) Z_{2}(t)+\ldots+a_{n}(t, s) Z_{n}(t)
\end{aligned}
$$

This can be achieved by assuming that $\mu$ itself is a linear function in $\vec{Z}(t)$ and letting $Z_{i}(t)$ be OU-processes. Alternatively, (24) can be viewed as a linearization of the "true" $\mu$ that is serving as its specification. The property we use for $\vec{Z}(t)$ to go from (23) to (24) is a linear property with regards to conditional expectation, which is shared by many processes, including OU processes. For validation of the measure change from $P$ to $Q$ with such a choice of $\mu$, please refer to [23], where the authors analyse measure change with state dependent Radon-Nikodym derivatives given by Ornstein-Uhlenbeck processes (including jumps) and RP is expressed as a weighted sum of the impact factors. This way, the KGB Linear Model is defined in (24).

\section{KGB METHOD OVERVIEW}

In this paper, a new KGB Method for RP calculation and the associated models are proposed. The analytical KGB Model is based on a robust stochastic process aimed at longterm RP forecasting, less suitable for predicting RP for weekly or daily futures products. The proposed KGB Method simplifies the computation of RP and is aimed at a broader audience of market actors beyond the specialized analytics departments of large energy traders.

The KGB Method is composed of three parts: KGB Model calculation, KGB Linear Model calibration, and KGB Linear Model use in forecasting, Fig. 2, as explained in this section.

KGB MODEL CALCULATION

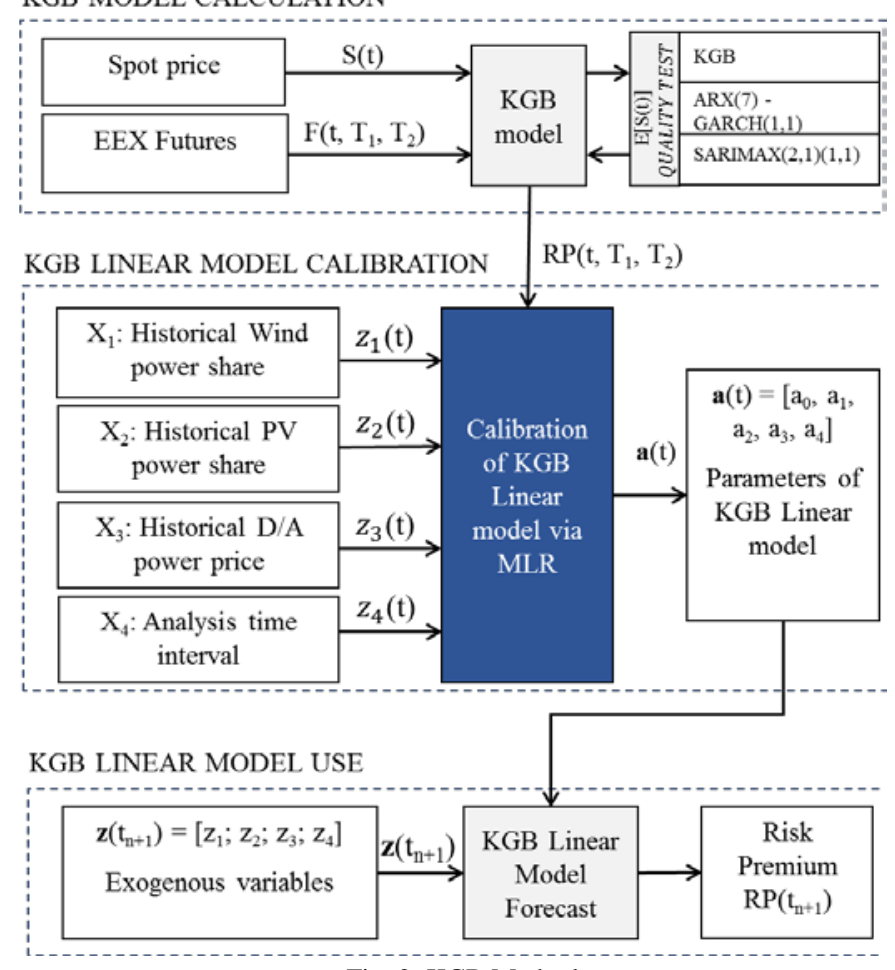

Fig. 2: KGB Method

The KGB Model, defined in (16), includes a KGB Price Sub-model, (15), that supplies the expected spot price $\mathbb{E}\left[S(T) \mid \mathfrak{I}_{t}\right]$. Since the actual values of RP are not known, the KGB Model was set up to calculate $\operatorname{RP}\left(t, T_{1}, T_{2}\right)$ with the help of $\mathbb{E}\left[S(T) \mid \mathfrak{I}_{t}\right]$, and the only way to validate the KGB Model results was to compare the quality of $\mathbb{E}\left[S(T) \mid \mathfrak{I}_{t}\right]$ forecasts by using back-casting comparison with the actual price data $S(t)$. For this purpose, the outputs of KGB Price Sub-model $\mathbb{E}\left[S(T) \mid \mathfrak{I}_{t}\right]$ were compared to the price forecast results from two other models, $\operatorname{ARX}(7)-G A R C H(1,1)$ and SARIMAX(2,1)(1,1), described in Section VI. The Quality Test in the top right of Fig. 2 compares the outputs of the models based on how well their output fit the past data. If the forecast error of KGB Price Sub-model is less or equal to the error in the other two models, the KGB Price Sub-model use is validated for its use in calculation of $\operatorname{RP}\left(t, T_{1}, T_{2}\right)$. 
To facilitate a broader use of RP forecasting, a KGB Linear Model was introduced in (24). In the following step of the KGB Method, Fig. 2, this model is calibrated using MLR according to Section V.

The mathematical derivation in Section III proves that the relation between the stochastic RP process and the exogenous variables can be described as a linear combination, via the KGB Linear Model, (24), and parameterized via MLR. Several exogenous variables are proposed in Section V. By using MLR we obtain regression parameters and other statistical quality measures of the estimation.

Using the calibrated KGB Linear Model, a market actor can run the RP forecast for any desired time period, Fig. 2; an example is presented in Section VIII-F. The market actor only needs four sets of exogenous data $\left[z_{1}, z_{2}, z_{3}, z_{4}\right]$ for a selected period in the future.

\section{RES PRODUCTION INFLUENCE ON RP}

To investigate the influence of the RES on RP development, we have correlated RP calculated using KGB Model with RES production, with the focus on PV and wind production. In the literature, expected price models related to several exogenous variables can be found that include drivers like wind production share, PV production share and consumption, [24], [24], [26]. Since RP is strongly related to time-to-maturity, [5], [6], it was chosen in addition to the three above already established exogenous variables.

Our assumption therefore was that the following four variables, influencing the behavior of the market participants, have the greatest impact on RP component of the electricity price: wind production share in the total production $z_{1}$, PV production share $z_{2}$, electricity consumption $z_{3}$, and time-tomaturity $z_{4}$. The ex-ante RP as stated in KGB Linear Model can be expressed as (25).

$$
\begin{gathered}
R\left(\mathrm{t}, T_{1}, T_{2}\right)=a_{0}\left(\mathrm{t}, T_{1}, T_{2}\right)+a_{1}\left(\mathrm{t}, T_{1}, T_{2}\right) z_{1}(\mathrm{t}) \\
+a_{2}\left(\mathrm{t}, T_{1}, T_{2}\right) z_{2}(\mathrm{t})+a_{3}\left(\mathrm{t}, T_{1}, T_{2}\right) z_{3}(\mathrm{t}) \\
+a_{4}\left(\mathrm{t}, T_{1}, T_{2}\right) z_{4}(\mathrm{t}) .
\end{gathered}
$$

To avoid correlation error between input variables, all inputs need to be exogenous to RP. Since wind and PV productions depend on weather conditions, and since their marginal production cost is near zero, the wind and PV power series can be treated as exogenous to price [24], consequently to RP. For the same reason, consumption can be treated as exogenous, too. To ensure that all exogenous variables are stationary, the Dickey-Fuller test, [24] was performed. The test results show that all exogenous variables used are stationary. The Belsley collinearity diagnostics was used on the variables and has shown no collinearity among them.

The analysis of RES production characteristics in Section VIII.D shows that the PV production has the greatest impact on price during the peak hours and the wind production has the greatest impact on price during the off-peak hours. Therefore, the KGB Linear Model has been run separately for two time periods within a day: peak hours (8:00 - 20:00) and off-peak hours (0:00-8:00 and 20:00-24:00). Two separate instances of the MLR were used to calibrate the model, using two separate RP time series obtained by the KGB Model, $\mathrm{R}_{P E A K}\left(t, T_{1}, T_{2}\right)$ for the peak period and $\mathrm{R}_{\text {off_PEAK }}\left(t, T_{1}, T_{2}\right)$ for the off-peak period.

\section{PRICE MOdEL COMPARISON}

In Section IV the RP model structure is presented which is strongly dependent on the relevance of its major components such as the estimated spot price $\mathbb{E}\left[S(T) \mid \mathfrak{J}_{t}\right]$. To confirm the relevance, two alternative stochastic price models were used: the ARX(7)-GARCH(1,1), [24], and the SARIMAX(2,1)(1,1), [25], in addition to the KGB Price Sub-model, (16). Ketterer acknowledges that strong mean reversion and seasonality are common for the spot price, so they should be included in the price model, [24]. Since all three considered price models comprise mean reversion and seasonality, they serve a similar purpose and could be used in KGB Model quality test, Fig. 2.

In the ARX(7)-GARCH(1,1) model, an autoregressive process is used to avoid overestimation of the variance and mean reversion driven by the volatile periods. The model comprises exogenous variables (wind and PV), as described by (26)-(27):

$$
\begin{aligned}
y_{\mathrm{t}}= & \mu+\sum_{i=1}^{l} \phi_{\mathrm{i}} \mathrm{y}_{\mathrm{t}-\mathrm{i}}+\sum_{j=1}^{m} \theta_{\mathrm{j}} \mathrm{w}_{\mathrm{t}-\mathrm{j}} \\
& +\sum_{j=1}^{m} Q_{\mathrm{j}} \mathrm{pv}_{\mathrm{t}-\mathrm{j}}+\varepsilon_{\mathrm{t}} \\
h_{\mathrm{t}}=\omega & +\sum_{i=1}^{q} \alpha_{\mathrm{i}} \varepsilon_{t-i}^{2}+\sum_{j=1}^{p} \beta_{\mathrm{j}} \mathrm{h}_{\mathrm{t}-\mathrm{j}} \\
& +\sum_{k=1}^{s} \gamma_{\mathrm{k}} \mathrm{w}_{\mathrm{t}-\mathrm{k}}+\sum_{k=1}^{s} \varpi_{\mathrm{k}} \mathrm{pv}_{\mathrm{t}-\mathrm{k}}
\end{aligned}
$$

Here $y_{\mathrm{t}}$ is $\log$ price and $h_{\mathrm{t}}$ conditional variance. Wind generation is expressed with $\mathrm{w}_{\mathrm{t}}, \mathrm{PV}$ generation with $\mathrm{pv}_{\mathrm{t}}$, where $\omega$ is the long-run variance, $\varepsilon_{\mathrm{t}}=\sqrt{\mathrm{h}_{\mathrm{t}}} \cdot \mathrm{z}_{\mathrm{t}}$ and $\mathrm{z}_{\mathrm{t}} \sim N I D(0,1)$; the rest are coefficients. As the model has to be stationary, the following requirements have to be met $\alpha_{\mathrm{i}} \cdot \beta_{\mathrm{j}}<$ 1 and $\left(\alpha_{\mathrm{i}} \wedge \beta_{\mathrm{j}}\right)>0$.

The SARIMAX $(2,1)(1,1)$ model proposed by Rintamäki et al., [26], aims to capture the influence of exogenous variables such as wind and PV to price volatility using seasonally adjusted autoregressive moving average, described by SARIMAX (p,q)(P,Q) model introduced by [27], (28).

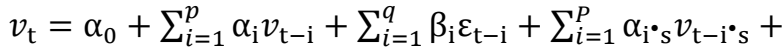

$$
\begin{aligned}
& \sum_{i=1}^{Q} \beta_{\mathrm{i} \cdot{ }_{\mathrm{s}}} \varepsilon_{\mathrm{t}-\mathrm{i} \cdot{ }^{\circ} \mathrm{s}}+\varepsilon_{\mathrm{t}}+\gamma^{T} \mathrm{x}_{t}
\end{aligned}
$$

Here $v_{\mathrm{t}}$ is an endogenous variable and $\mathrm{x}_{t}$ represents the exogenous variables at the time $t$. The number of autoregressive terms of $v_{\mathrm{t}-\mathrm{i}}$ is $p$, where the number of moving average terms of $\varepsilon_{\mathrm{t}-\mathrm{i}}$ is $q . P$ is a seasonal autoregressive term of $v_{\mathrm{t}-\mathrm{i} \cdot \mathrm{s}}$ with a periodicity of $\mathrm{s}$ and $Q$ is a seasonal moving average term for $\varepsilon_{\mathrm{t}-\mathrm{i}}{ }^{*} \mathrm{~s}$ with the periodicity of s. Coefficients are represented by $\alpha_{\mathrm{i}}, \beta_{\mathrm{i}}, \alpha_{\mathrm{i} \cdot \mathrm{s}}$ and $\beta_{\mathrm{i} \cdot \mathrm{s}}$. 


\section{ELECTRICITY MARKET OVERVIEW}

The German electricity market is suitable to test the proposed KGB Linear Model as it is one of the most liquid markets in Europe, [28]. The German market attracts market participants from all over Europe because energy traded there can be delivered in several European countries. Consequently, the presence of most market participants in the German market brings additional liquidity for products delivered in Germany.

The German electricity market comprises several markets, including a long-term market (forwards and futures), [29], as well as short-term spot and intraday markets, [30]. The products traded in the long-term market are mainly divided in those traded on Over The Counter (OTC) and those on the organized power exchange EEX, [29], [31]. The OTC products are based on the EFET contracts and are cleared only between the counterparties. The products traded on EEX are cleared on European Commodity Clearing (ECC), [32].

The short-term markets in Germany are organized by the EPEX Spot power exchange, typically involving spot and intra-day markets. On the spot market, the market participants can trade with the hourly products on the auction trading based on the uniform market clearing price on EPEXDAY Ahead, [30]. EPEXDAY Ahead auction market is adequate to quantify the influence of RES production on the electricity price and on RP due to its size and transparent public market price signal.

\section{RESULTS}

In the research data from German electricity markets, EEX (the futures market related to delivery in German) and EPEX Spot (EPEXDAY Ahead auction for the day ahead (spot) market for delivery in Germany) have been used.

- The first set of data used was historical hourly data of day ahead market from January $1^{\text {st }}, 2011$ to August 31 ${ }^{\text {st }}, 2014$ with delivery in Germany. Those data were used to determine the estimated spot price $\mathbb{E}\left[S(T) \mid \mathfrak{I}_{t}\right]$ and deterministic part $\bar{\Lambda}\left(T_{1}, T_{2}\right)$ in the future period of September $1^{\text {st }}$, 2014 to December $31^{\text {st }}$, 2015 for Germany, [33].

- The futures market EEX has provided us with the traded data in 2014 for delivery of the annual product (F1BY, [29]) for the year 2015 for Germany as well, [34].

- The daily production of solar PV and wind production in Germany for the 5-year period from January $1^{\text {st }} 2011$ to August $31^{\text {st }} 2014$ was used to determine the correlation factors in (26) by MLR, [35].

- $\quad$ For MLR we have used raw data of German electricity consumption for the same period, [36].

\section{A. Data Analysis: Exogenous Variables}

Before exogenous variables (spot price, wind generation, PV generation) could be used in all three price models, all key criteria, relating to stationary and levels of seasonality, autocorrelation and partial autocorrelation, must be tested.
The results of Dickey-Fuller test show that spot price is not stationary. The price signal contains a trend and a differentiation (D element) of 2. After filtering the price signal for differentiation and trend, and after removing the monthly seasonal pattern, the remaining signal can be regarded as stochastic. Next, the logarithm of price time series for peak and off-peak are created. Time series for German market dayahead price and logarithm of price are shown on Fig. 3 for peak and off-peak periods, respectively.
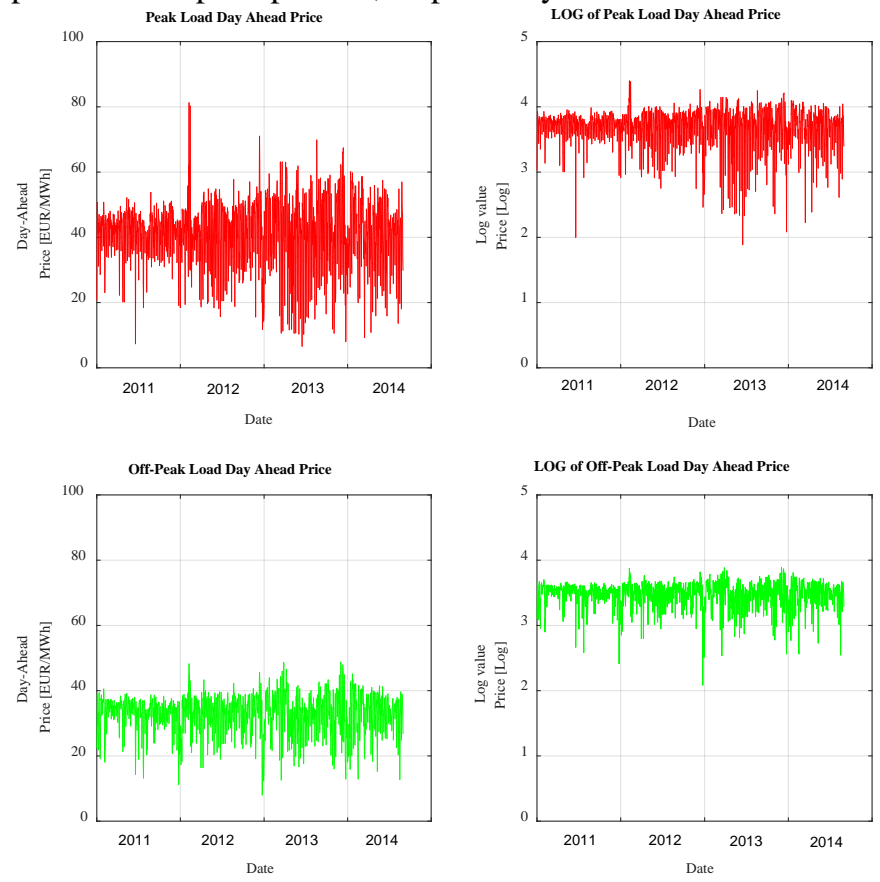

Fig. 3: German market: De-seasonalized spot price and its logarithm rendition

The de-seasonalized spot price is used to apply the autocorrelation function (ACF) and the partial autocorrelation function (PACF) on peak and off-peak time series. The results in Fig. 4 show that the weekly pattern remains with a lag of 7. This indicates that the residuals have $7^{\text {th }}$-degree seasonal integration, which prevents PACF to tail-off, so the seasonal component needs to be removed for the input data to be suitable for use. Those results are an example of customers' weekly consumption behavior pattern, reflected in the spot prices. After removing the weekly seasonal effect, that pattern is not present any longer. 

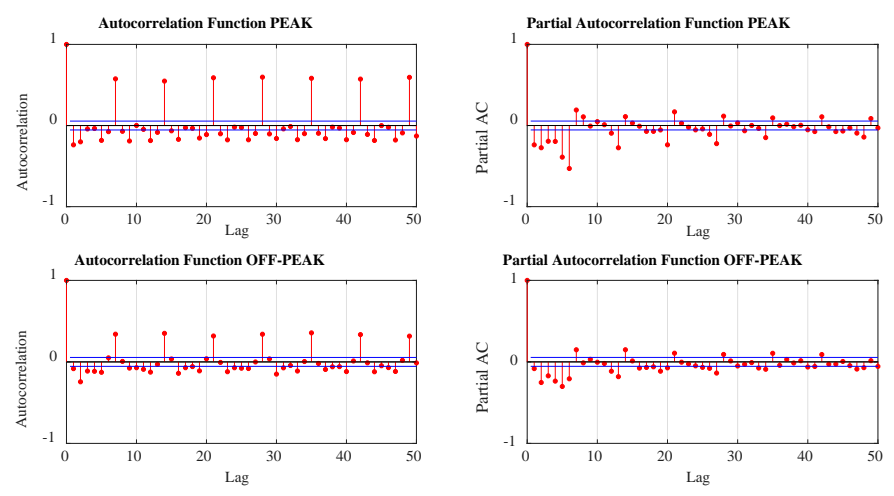

Fig. 4: Statistics of the German market: ACF and PACF for $1^{\text {st }}$ differential of the electricity spot price

For other exogenous variables such as wind generation and PV generation, Fig. 5, their share in the total electricity production mix was calculated, as such normalized form is better suited for use in the price models in Section VI, [26].
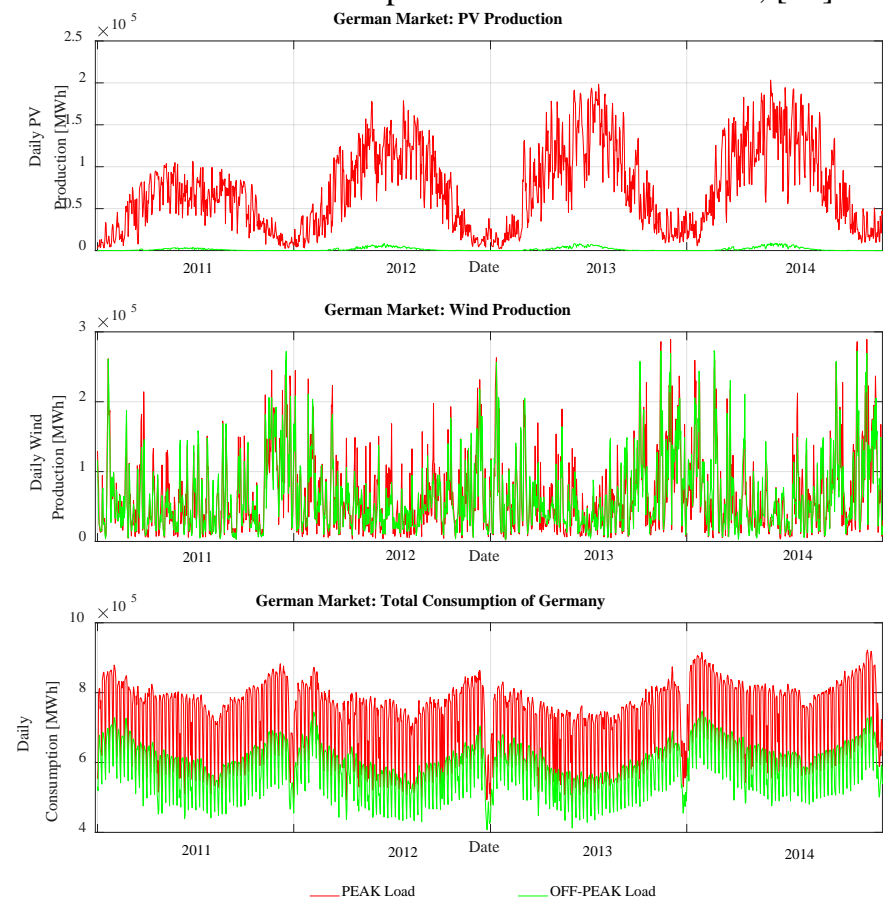

Fig. 5: German Daily Wind and PV generation and Consumption.

\section{B. Results of Price Model Comparison}

The key element for RP calculation relies on the quality of estimated spot price $\mathbb{E}\left[S(T) \mid \mathfrak{I}_{t}\right]$. To test KGB Price Submodel relevance, its forecast error is compared to the performance of two other price models. The model-supplied price forecast was compared to the actual values in a backcasting process, providing the forecast error. Based on Sections IV, V and VI, three price models were used for the same time frame: KGB Price Sub-model, ARX(7)GARCH(1,1) and SARIMAX(2,1)(1,1). Two separate instances of each model were run (peak and off-peak) to compare the differences in the intraday dynamics.
The comparison covered the $\mathbb{E}\left[S(T) \mid \mathfrak{I}_{t}\right]$ mean values and the associated confidence intervals for all three price models separately for the two instances. The daily mean values of all forecasts are presented in Fig. 6, from September $1^{\text {st }}, 2014$ to December $31^{\text {st }}, 2015$. The same figure shows the actual electricity price values in two parts: the full line presents pre-sampled period, and the dotted line presents actuals in the forecast period. Fig. 6 shows that KGB Price Sub-model and the ARX(7)-GARCH(1,1) provide similar results and are close to the actual price values whereas the SARIMAX $(2,1)(1,1)$ exhibits a stronger decline and therefore provides lower forecast values, with consequently greater error compared to the actual values. TABLE I shows the results of all three models for the peak and off-peak instances. The second column group displays different time frames within the same forecasting period.

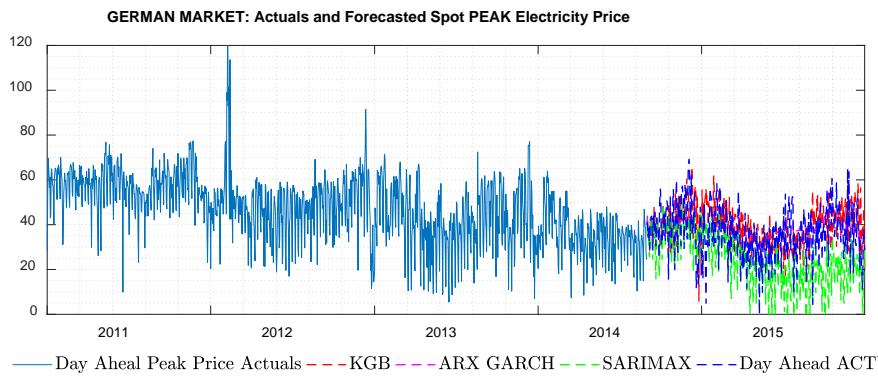

- Day Aheal Peak Price Actuals - - -KGB - - -ARX GARCH - - -SARIMAX - - - Day Ahead ACT GERMAN MARKET: Actuals and Forecasted Spot Off-PEAK Electricity Price

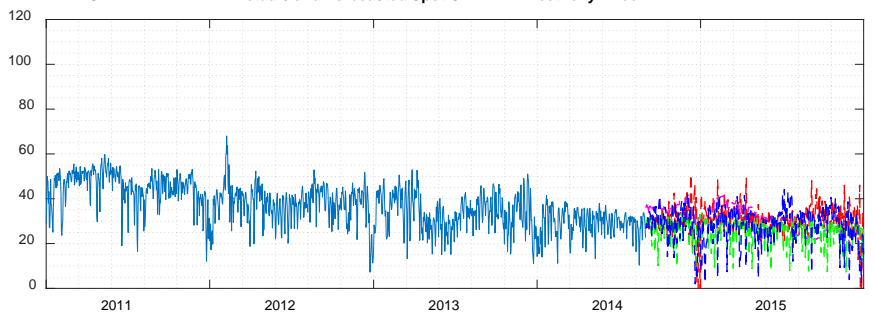

Fig. 6: Forecast results of three stochastic models

The first data column group shows the mean values of the forecasted instances for different time-periods, and the second group shows the values of forecast errors compared to the actuals in [\%]. These values were used to calculate the average MAPE (Mean Absolute Percentage Error) values for the entire forecast period. For KGB Price Sub-model, average MAPE is $12.2 \%$, for ARX-GARCH $15.7 \%$ and for SARIMAX $23.0 \%$. The last column group shows the share of instances with violations of confidence level in the forecast period in [\%]. The average monthly violation levels for the forecast period are similar in all models, where the lowest is for KGB Price Sub-model with $2.7 \%$, followed by ARXGARCH with $2.8 \%$ and SARIMAX with $2.9 \%$.

The results show that the KGB Price Sub-model on average provides better results compared to the other two models presented. Therefore, the KGB Price Sub-model is adequate for long-term spot price forecasting, and hence suitable to be used in the KGB Model calculation. 
TABLE I

COMPARISON OF PRICE FORECAST RESULTS TO ACTUAL VALUES

\begin{tabular}{|c|c|c|c|c|c|c|c|}
\hline \multirow[b]{2}{*}{\begin{tabular}{|c|} 
Est. Spot \\
Price \\
Models \\
\end{tabular}} & \multirow[b]{2}{*}{$\begin{array}{l}\text { Time } \\
\text { frame }\end{array}$} & \multicolumn{2}{|c|}{ FORECAST MEAN } & \multicolumn{2}{|c|}{ ERROR TO ACTUAL } & \multicolumn{2}{|c|}{ VIOLATION SHARE } \\
\hline & & $\begin{array}{l}\text { PEAK } \\
\text { [EUR/ } \\
\text { MWh] }\end{array}$ & $\begin{array}{c}\text { OFF } \\
\text { PEAK } \\
{[\text { EUR/ }} \\
\text { MWh] }\end{array}$ & $\begin{array}{c}\text { PEAK } \Delta \\
\text { to Act }\end{array}$ & $\begin{array}{c}\text { OFF } \\
\text { PEAK } \Delta \\
\text { to Act }\end{array}$ & $\begin{array}{l}\text { PEAK } \\
\text { VIOL. }\end{array}$ & $\begin{array}{l}\text { OFF- } \\
\text { PEAK } \\
\text { VIOL. }\end{array}$ \\
\hline \multirow{16}{*}{ KGB } & sep.14 & 37.10 & 29.53 & $4 \%$ & $5 \%$ & $2.2 \%$ & $1.2 \%$ \\
\hline & okt.14 & 39.34 & 29.20 & $4 \%$ & $1 \%$ & $2.8 \%$ & $2.0 \%$ \\
\hline & nov.14 & 46.58 & 31.91 & $-6 \%$ & $-9 \%$ & $3.4 \%$ & $1.7 \%$ \\
\hline & dec.14 & 43.10 & 25.72 & $-5 \%$ & $-2 \%$ & $0.6 \%$ & $2.6 \%$ \\
\hline & jan.15 & 47.80 & 32.30 & $-36 \%$ & $-40 \%$ & $5.0 \%$ & $0.6 \%$ \\
\hline & feb.15 & 43.79 & 32.78 & $-4 \%$ & $-5 \%$ & $4.0 \%$ & $2.0 \%$ \\
\hline & mar.15 & 38.88 & 32.56 & $-13 \%$ & $-15 \%$ & $2.5 \%$ & $1.9 \%$ \\
\hline & apr.15 & 35.76 & 31.97 & $-19 \%$ & $-6 \%$ & $3.7 \%$ & $2.9 \%$ \\
\hline & maj.15 & 32.50 & 29.31 & $-24 \%$ & $-19 \%$ & $4.2 \%$ & $2.4 \%$ \\
\hline & jun.15 & 32.41 & 28.59 & $-2 \%$ & $-1 \%$ & $4.9 \%$ & $4.5 \%$ \\
\hline & jul.15 & 31.43 & 29.22 & $15 \%$ & $12 \%$ & $1.8 \%$ & $2.3 \%$ \\
\hline & avg.15 & 31.70 & 28.96 & $5 \%$ & $3 \%$ & $4.6 \%$ & $0.0 \%$ \\
\hline & sep.15 & 43.64 & 36.70 & $-25 \%$ & $-26 \%$ & $3.1 \%$ & $2.7 \%$ \\
\hline & okt.15 & 41.49 & 32.46 & $7 \%$ & $5 \%$ & $2.4 \%$ & $4.8 \%$ \\
\hline & nov.15 & 45.24 & 31.01 & $-16 \%$ & $-20 \%$ & $0.4 \%$ & $4.6 \%$ \\
\hline & dec.15 & 42.85 & 23.61 & $-27 \%$ & $-9 \%$ & $1.9 \%$ & $3.6 \%$ \\
\hline \multirow{16}{*}{$\begin{array}{l}\text { ARX- } \\
\text { GARCH }\end{array}$} & sep.14 & 38.26 & 36.00 & $1 \%$ & $-16 \%$ & $3.5 \%$ & $1.6 \%$ \\
\hline & okt.14 & 38.82 & 35.58 & $5 \%$ & $-20 \%$ & $4.3 \%$ & $4.5 \%$ \\
\hline & nov.14 & 40.43 & 37.87 & $8 \%$ & $-29 \%$ & $3.3 \%$ & $2.1 \%$ \\
\hline & dec.14 & 36.87 & 33.59 & $10 \%$ & $-33 \%$ & $4.6 \%$ & $5.5 \%$ \\
\hline & jan.15 & 34.39 & 32.44 & $2 \%$ & $-41 \%$ & $3.1 \%$ & $1.8 \%$ \\
\hline & feb.15 & 38.98 & 40.66 & $7 \%$ & $-30 \%$ & $4.0 \%$ & $4.9 \%$ \\
\hline & mar.15 & 35.45 & 37.35 & $-3 \%$ & $-32 \%$ & $3.6 \%$ & $0.4 \%$ \\
\hline & apr.15 & 34.42 & 35.53 & $-14 \%$ & $-18 \%$ & $1.4 \%$ & $1.7 \%$ \\
\hline & maj.15 & 32.06 & 31.72 & $-23 \%$ & $-29 \%$ & $0.7 \%$ & $4.5 \%$ \\
\hline & jun.15 & 36.21 & 30.78 & $-13 \%$ & $-9 \%$ & $0.6 \%$ & $5.0 \%$ \\
\hline & jul.15 & 40.18 & 28.94 & $-9 \%$ & $13 \%$ & $0.6 \%$ & $1.5 \%$ \\
\hline & avg.15 & 38.49 & 23.56 & $-15 \%$ & $21 \%$ & $2.8 \%$ & $4.7 \%$ \\
\hline & sep.15 & 38.99 & 22.31 & $-12 \%$ & $24 \%$ & $4.3 \%$ & $0.5 \%$ \\
\hline & okt.15 & 45.22 & 26.51 & $-1 \%$ & $22 \%$ & $1.5 \%$ & $1.9 \%$ \\
\hline & nov.15 & 39.76 & 23.16 & $-2 \%$ & $11 \%$ & $4.0 \%$ & $2.5 \%$ \\
\hline & dec.15 & 36.22 & 16.97 & $-7 \%$ & $22 \%$ & $1.2 \%$ & $2.0 \%$ \\
\hline \multirow{16}{*}{$\begin{array}{l}\text { SARI } \\
\text { MAX }\end{array}$} & sep.14 & 33.03 & 26.77 & $15 \%$ & $13 \%$ & $0.4 \%$ & $0.7 \%$ \\
\hline & okt.14 & 36.69 & 29.01 & $10 \%$ & $2 \%$ & $0.4 \%$ & $4.2 \%$ \\
\hline & nov.14 & 36.39 & 26.55 & $17 \%$ & $9 \%$ & $3.7 \%$ & $0.6 \%$ \\
\hline & dec.14 & 34.84 & 26.13 & $15 \%$ & $-3 \%$ & $5.4 \%$ & $1.8 \%$ \\
\hline & jan.15 & 34.77 & 26.92 & $1 \%$ & $-17 \%$ & $5.8 \%$ & $0.6 \%$ \\
\hline & feb.15 & 31.95 & 27.29 & $24 \%$ & $13 \%$ & $2.3 \%$ & $4.3 \%$ \\
\hline & mar.15 & 25.96 & 25.34 & $24 \%$ & $10 \%$ & $4.1 \%$ & $3.0 \%$ \\
\hline & apr.15 & 20.26 & 25.29 & $33 \%$ & $16 \%$ & $4.1 \%$ & $4.6 \%$ \\
\hline & maj.15 & 18.85 & 26.61 & $28 \%$ & $-8 \%$ & $3.4 \%$ & $2.1 \%$ \\
\hline & jun.15 & 18.24 & 25.58 & $43 \%$ & $9 \%$ & $3.1 \%$ & $5.0 \%$ \\
\hline & jul.15 & 15.01 & 24.44 & $59 \%$ & $26 \%$ & $4.1 \%$ & $0.9 \%$ \\
\hline & avg.15 & 13.21 & 24.14 & $61 \%$ & $19 \%$ & $5.4 \%$ & $3.5 \%$ \\
\hline & sep.15 & 18.47 & 26.43 & $47 \%$ & $10 \%$ & $6.0 \%$ & $0.9 \%$ \\
\hline & okt.15 & 18.69 & 24.31 & $58 \%$ & $29 \%$ & $1.3 \%$ & $1.3 \%$ \\
\hline & nov.15 & 18.87 & 23.22 & $51 \%$ & $10 \%$ & $1.7 \%$ & $0.5 \%$ \\
\hline & dec.15 & 20.50 & 25.02 & $39 \%$ & $-15 \%$ & $5.5 \%$ & $2.7 \%$ \\
\hline
\end{tabular}

\section{Risk Premium Calculation}

In the KGB Model, RP is calculated with the three main components (15)-(16). The first component is determined in the market $\mathcal{F}\left(t, T_{1}, T_{2}\right)$ as a result of daily futures trades. The second component $\bar{\Lambda}\left(T_{1}, T_{2}\right)$ is a deterministic component expressing the seasonal effect that was forecast with the use of standard moving average approach taking into account all specifics such as type of the day, bridge days, daylight saving time, Monday mornings, Friday afternoons etc. The third component $[S(t)-\Lambda(t)] \cdot \Omega\left(t, T_{1}, T_{2}\right)$ is driven by the Omega factor, (17). It is important to note that since the futures price $\mathcal{F}\left(t, T_{1}, T_{2}\right)$ is only available for base and peak periods instead of for hourly level, RP is also only calculated for these periods (base, peak and off-peak).

RP was calculated for the observation period from January $1^{\text {st }}, 2014$ up to August $31^{\text {st }}, 2014$. The observation time horizon is hence 12 months including the entire year prior to the delivery period $\left[T_{1}, T_{2}\right]$ and was also used to calibrate our model using MLR.

Fig. 7 shows the results of RP calculation using KGB Model for the period of Jan $1^{\text {st }}$, to Aug $31^{\text {st }}$, 2014 with the back-casting estimation of the RP using KGB Linear Model shown for reference (dashed line). The KGB Model provides the range of $R P \in[2.97,20.83]$ EUR/MWh with a mean of 9.58 EUR/MWh for peak and [-2.56, 2.11] EUR/MWh with a mean of 0.52 EUR/MWh for off-peak. The results of peak hours exhibit high volatility of RP, with maximum jumps of $+87 \%$ for bridge-days and $+147 \%$ within 5 consecutive days. We confirm assumption from the research, [13], considering $\mathrm{RP}$ to be positive in the mid-term period prior to time-tomaturity. In general overview the RP is positive for peak, still highly volatile, where off-peak RP exhibits frequently negative values.
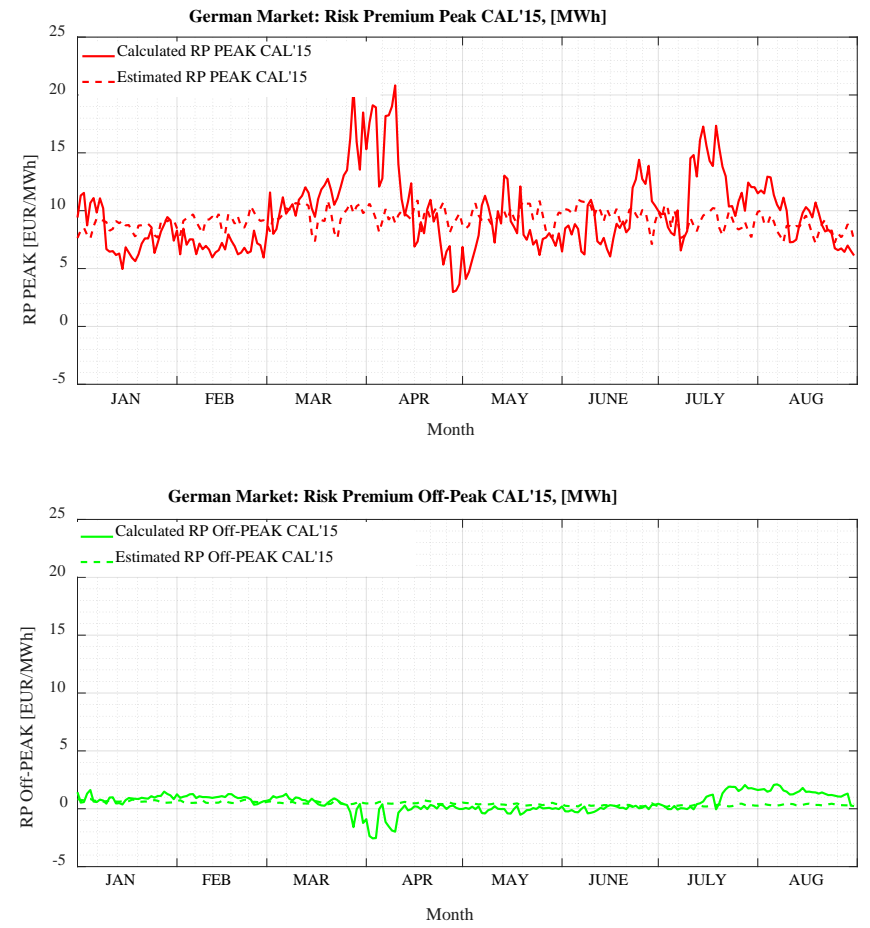

Fig. 7. Risk Premium development

In the top panel of the Fig. 7 for the period from the end of March to mid-April we assume that the results of the calculated peak's RP can be associated with the purchase strategy of the demand (bid) side pushing the RP much higher 
than expected according to the long-term predictions. Consequently, RP increases from $10 \mathrm{EUR} / \mathrm{MWh}$ up to the level of $20 \mathrm{EUR} / \mathrm{MWh}$.

In the following time segment from mid-April to mid-May, we assume that the increased RP leads to an increase in the supply (ask) side with additional energy offered in the market. This additional energy offer drives RP towards an equilibrium between the bid and ask sides in mid-April up to the point when the ask side becomes larger than the bid side, pushing the futures prices down. We believe that the sudden shift in the value of RP below the estimated equilibrium value is associated with a higher push of the ask side decreasing the value of RP from 20 EUR/MWh to the value of 3 EUR/MWh at the end of April. At that value level, peak product RP is underestimated; it incites the bid side to increase until RP converges to the market acceptable value level. Based on the results shown in Fig. 7 we assume that for the annual peak product, the market acceptable value of RP is approximately 10 EUR/MWh.

The results of the estimation fit well to calculated data, however estimation is unable to capture RP adequately during the high volatility periods. The high value of RP opens a new chapter in the understanding of RP, therefore further clarification is required.

The results of RP calculation using KGB Model, presented in the top panel of the Fig. 7, are a combination of the market acceptable long-term mean value of RP, (approximately 10 EUR/MWh), the short-term Futures deviation from a mediumterm trend (e.g. a mean), the largest short-term DA price forecast change and the forecast error.

Fig. 8 aims to provide additional insight into the RP results for the Peak products. In the top panel, the yellow shaded area represents RP as a difference between the traded Futures product for 2015 (yearly peak product, F1PY CAL'15, red dashed line) and the Expected day-ahead (DA) price estimated using KGB Price sub-model (blue dashed line). All three values are determined during 2014 reflecting the expectations for 2015. The actual 2015 DA prices are shown as the annual medium-term mean value (green line). In the bottom panel, the actual 2014 DA prices (grey line) are shown compared to the prices estimated with the KGB Price sub-model (KGB PSM, dashed blue).

The peak prices shown in the top panel of Fig. 8 indicate how much the value of the Futures peak CAL'15 differs from the actual 2015 DA. The "Focus Area" (black rectangle) contains the largest peak product RP values ranging between [18.18, 20.53] EUR/MWh. These high RP values can be associated with a significant downward trend of the DA prices in Q1 of 2014 (as indicated by a black arrow). That trend lasted over two months and has been captured in the RP calculated by the KGB model, with the highest RP value of 20.53 EUR/MWh.

The price dynamics in the Off-peak products features the values smaller than in the Peak products; however, the mechanisms shown in Fig. 8 are valid for both products.
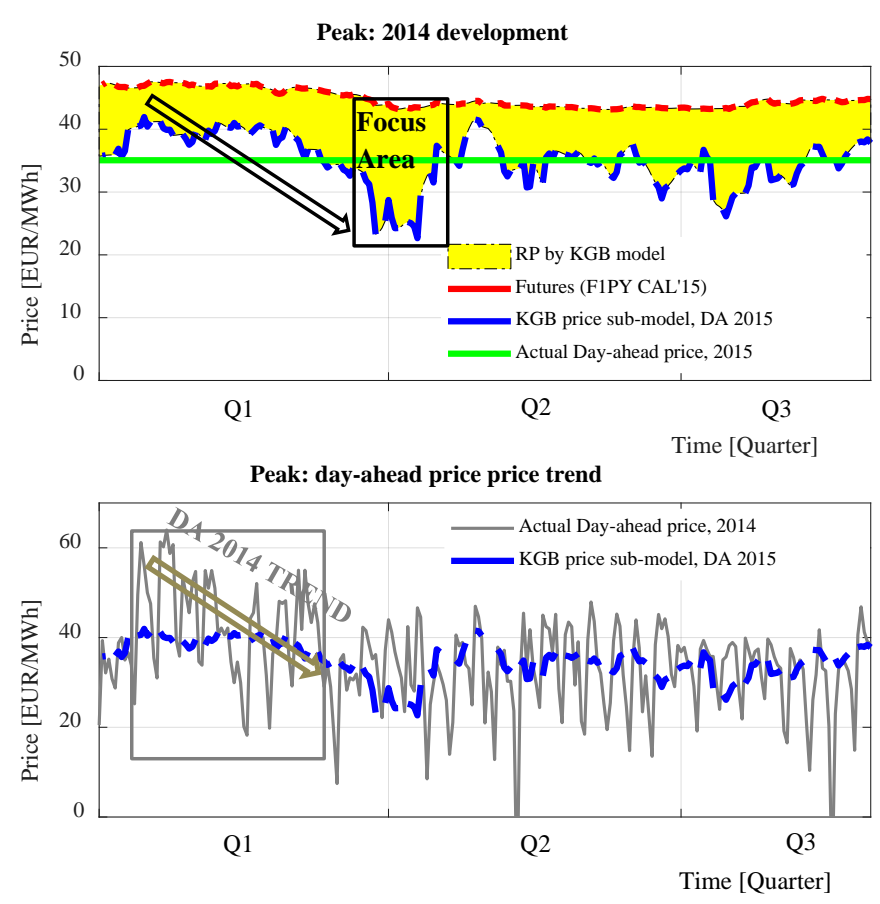

Fig. 8: Relationships of RP to Futures and estimated day-ahead prices

In TABLE II, the Focus Area RP results indicated in Fig. 8 are presented indicating RP values where significant development takes place in the actual 2014 DA prices. There a change in the DA trend led to a start of the mean reversion process of the Expected DA prices to their long-term mean value.

TABLE II

RISK PREMIUM IN THE FOCUS AREA

\begin{tabular}{ccccccccc}
\hline YEAR & MONTH & DAY & F1PY & F1OY & $\begin{array}{c}\text { KGB } \\
\text { PSM } \\
\text { PEAK }\end{array}$ & $\begin{array}{c}\text { KGB } \\
\text { PSM } \\
\text { OffPEAK }\end{array}$ & $\begin{array}{c}\text { RP } \\
\text { PEAK }\end{array}$ & $\begin{array}{c}\text { RP } \\
\text { OffPEAK }\end{array}$ \\
\hline 2014 & 3 & 24 & 45.2 & 29.68 & 33.17 & 29.24 & 12.03 & 0.44 \\
2014 & 3 & 25 & 44.87 & 29.62 & 31.81 & 29.22 & 13.06 & 0.40 \\
2014 & 3 & 26 & 44.75 & 29.56 & 31.25 & 29.24 & 13.50 & 0.32 \\
2014 & 3 & 27 & 44.57 & 29.24 & 28.32 & 29.52 & 16.25 & -0.28 \\
2014 & 3 & 28 & 43.82 & 28.83 & 23.29 & 30.42 & 20.53 & -1.59 \\
2014 & 3 & 31 & 43.92 & 28.90 & 25.43 & 30.13 & 18.49 & -1.23 \\
2014 & 4 & 1 & 44.05 & 28.95 & 28.74 & 29.85 & 15.31 & -0.90 \\
2014 & 4 & 2 & 43.5 & 28.48 & 25.89 & 30.84 & 17.61 & -2.36 \\
2014 & 4 & 3 & 43.35 & 28.50 & 24.24 & 31.06 & 19.11 & -2.56 \\
2014 & 4 & 4 & 43.2 & 28.52 & 24.27 & 31.05 & 18.93 & -2.53 \\
2014 & 4 & 7 & 43.42 & 28.96 & 25.24 & 30.10 & 18.18 & -1.14 \\
2014 & 4 & 8 & 43.29 & 28.83 & 25.05 & 30.36 & 18.24 & -1.53 \\
2014 & 4 & 9 & 43.51 & 28.71 & 24.50 & 30.59 & 19.01 & -1.88 \\
2014 & 4 & 10 & 43.48 & 28.74 & 22.65 & 30.72 & 20.83 & -1.98 \\
2014 & 4 & 11 & 43.45 & 29.21 & 29.43 & 29.55 & 14.02 & -0.34 \\
2014 & 4 & 14 & 43.80 & 29.28 & 33.01 & 29.42 & 10.79 & -0.14 \\
\hline
\end{tabular}

If the trend of the actual 2014 DA prices would have continued further, the Futures values F1PY CAL'15 would have entirely detached from the actual 2015 DA price value. In our case, the Futures prices have only partially detached, and while the KGB Price sub-model has consequently slightly overestimated the 2015 DA price, the model forecast has quickly reverted to mid-term mean. Our analysis shows that most of the time, the KGB Price sub-model provided an adequate prediction of the future DA 2015 price. 
The valuable calculation of the short-term difference between the day-ahead and real-time prices is presented in the Potomac report, [37]. The difference is presented as a premium that market participants are willing to pay to eliminate the day-ahead production price risk. The short-term Risk Premium was calculated using the "ex-post" approach (denoted as $\mathrm{RP}_{\mathrm{EP}}$ ) as in the Potomac report in the period between Jan $1^{\text {st }} 2014$ and Aug 31 $31^{\text {st }}$ 2014. During that period the short-term $\mathrm{RP}_{\mathrm{EP}}$ is considered to be extremely high, ranging within $[-100.65,+74.00]$ EUR/MWh, TABLE III. The values of the settlement prices for the same time period are lower, ranging within [-42.23, 31.88] EUR/MWh, still much higher than the long-term $\mathrm{RP}_{\mathrm{EP}}$ of the peak product.

$$
\text { TABLE III }
$$

RISK PREMIUM: SHORT-TERM “EX-POST” POTOMAC APPROACH

\begin{tabular}{|c|c|c|c|c|}
\hline & $\begin{array}{l}\text { POTOMAC Approach } \\
\mathbf{R P}(\mathbb{E P}) \text { to Weight }\end{array}$ & $\begin{array}{l}\text { POTOMAC Approach } \\
R P(\mathbb{P P}) \text { to Low }\end{array}$ & $\begin{array}{l}\text { POTOMAC Approach } \\
\text { RP(EP) to High }\end{array}$ & $\begin{array}{l}\text { POTOMAC Approach } \\
\text { RP(EP) to Last }\end{array}$ \\
\hline \multicolumn{5}{|l|}{ BESE } \\
\hline Min & -25.11 & -6.03 & -58.74 & -40.08 \\
\hline Mean & -0.03 & 8,00 & -8.78 & -0.06 \\
\hline MAPE & 3.67 & 8.09 & 9.05 & 5.13 \\
\hline Max & 25.46 & 39.66 & 16.39 & 25.33 \\
\hline \multicolumn{5}{|l|}{ PE.AK } \\
\hline Min & 42.23 & $-5,00$ & -100.65 & -68.2 \\
\hline Mean & -0.06 & 8.78 & -9.93 & -0.17 \\
\hline MAPE & 5.13 & 8.90 & 10.36 & 6.91 \\
\hline Max & 31.88 & 74,00 & 22.75 & 45.26 \\
\hline \multicolumn{5}{|l|}{ OFF-PEAK } \\
\hline Min & -15.28 & -7.37 & -44.95 & -26.4 \\
\hline Mean & 0.01 & 7.27 & -7.65 & 0.05 \\
\hline MAPE & 2.86 & 7.35 & 7.80 & 4.47 \\
\hline Max & 23.53 & 51.62 & 10.03 & 28.21 \\
\hline
\end{tabular}

To investigate the relationship between the short-term "expost" $\mathrm{RP}_{\mathrm{EP}}$ and the long-term "ex-ante" $\mathrm{RP}$, as well as between the short-term "ex-post" $\mathrm{RP}_{\mathrm{EP}}$ and long-term "expost” $\mathrm{RP}_{\mathrm{EP}}$, correlation analysis has been performed. All correlation factors are low, ranging between 0.06 and 0.27 . The analysis using German market data did not provide any evidence by which a short-term $\mathrm{RP}_{\mathrm{EP}}$ calculated with "expost" approach would be connected to the value of the longterm "ex-ante" RP.

\section{Characteristics of RES Production}

To assess the RES production influence on electricity price and RP, their temporal behavior needs to be understood. Therefore, the respective temporal characteristics of the 5year PV- and wind production hourly time series were investigated. Separately for each time series, the matching hours were summed per year and normalized to the highest hourly value of the five data points. The resulting normalized 5-year average values are shown in Fig. 8 and Fig. 9 with red being the highest and dark blue the lowest value.

PV production exhibits a strong seasonal effect, with the strongest impact expected from March to September where the diurnal effect is strong as well. The strongest impact during the day is between 11:00 and 17:00, as shown in Fig. 8.

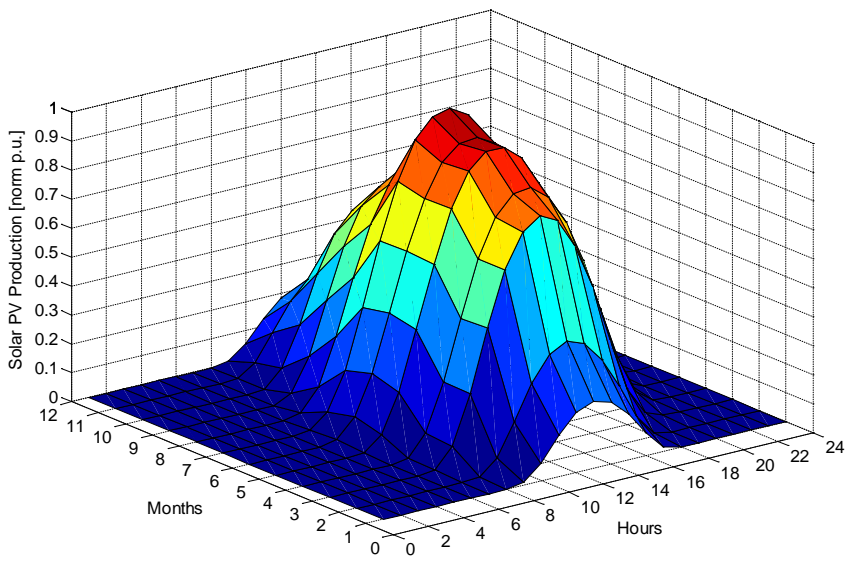

Fig. 9. PV production characteristics

Wind production characteristics are shown in Fig. 9, exhibiting a seasonal effect as well, with the strongest impact expected from November to January. The strongest impact is expected during the daytime from 08:00 to 14:00 followed by the interval from 19:00 to 24:00. The weakest impact is expected from April to August. During that period, the diurnal effect is divided into two time periods. The smallest impact is expected during the daytime from 06:00 to 10:00 followed by an interval from 16:00 to 19:00.

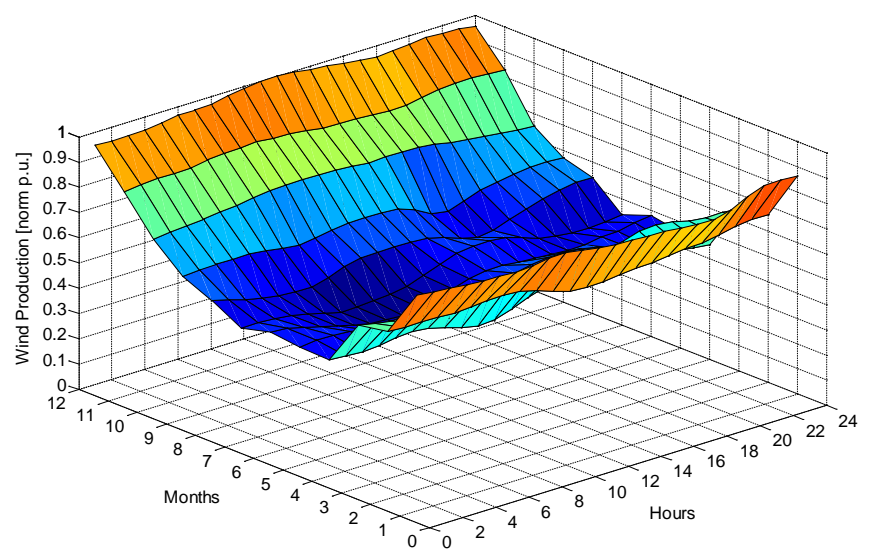

Fig. 10. Wind production characteristics

The results show that the PV and wind production are complementary in a generation portfolio, therefore constituting an ideal portfolio of electricity production mix for the producers.

\section{E. Correlation Results}

The impact of RES production on RP has been investigated using the correlation method. Since the correlation of RP to RES production could depend on the share of RES production in total electricity production mix, the respective RES production share of $\mathrm{PV}$ and wind in the production mix was used as a proxy.

\section{1) Correlation between Electricity Price and RES}

To determine the correlation factors between the RES 
production and electricity price, the calculation was based on a 5-year horizon from 2010 to 2014 covering more than 105,000 data records. Due to a possible correlation error associated with negative price values, the negative prices were excluded. In the period from January $1^{\text {st }}, 2011$ to December $31^{\text {st }} 2014,64$ negative values out of total number 38,592 have been excluded. Had those negative prices been included in the calculations, it would lead to the following errors: for wind vs. price in 15 out of 288 correlation results, the error would be $(\mathrm{min} / \mathrm{mean} / \max [-0.05 ;-0.01 ; 0.02])$ and for PV in 14 out of 288 correlation results, the error would be $(\mathrm{min} / \mathrm{mean} / \mathrm{max}[-$ $0.03 ;-0.02 ; 0.00])$.

The correlation calculated for the entire time horizon is negative, yet very low, i.e. $4.8 \%$ for PV and $6 \%$ for wind. Hence the correlation time window was reduced to a month for each hour of the day. Since RES production does not depend on a day type, further segmentation by day type was not needed. Correlation factors are shown in Fig. 10 for PV production share and in Fig. 11 for wind production share.

The results in Fig. 10 show that the PV production share exhibits a strong negative correlation to electricity price up to -0.77 on average per month. The month with the strongest hourly average negative correlation, $[-0.52,-0.77]$ is September in the daily period between 07:00 and 21:00. Fig. 10 also shows a strong correlation of PV in July during morning hours between 06:00 and 08.00 and in the evening hours between 16.00 and 22.00 .

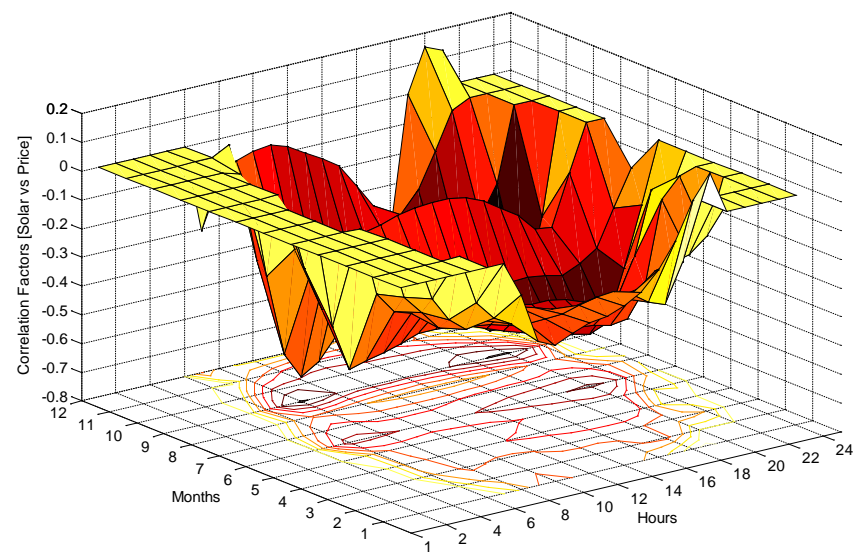

Fig. 11. Correlation of PV production share vs. price

Wind production share in Fig. 11 exhibits a seasonal effect as well, with and the strongest influence on electricity price between April and May and between September and October. Average hourly correlation levels within $[-0.18,0.26]$ are observed. The strongest wind production is during the period of consumption morning ramp. During this period, the dynamics of electricity production mix is the greatest compared to the rest of the day. In that period, several different types of conventional generation are switched on in order to follow the expected morning increase of consumption. At the same time, the empirical analysis in Fig. 11 shows that the wind generation on average has the greatest increase in its production between 7:00 and 14:00. High dynamics in electricity production mix levels would need further analysis to clarify the extent of wind generation contribution to price shift in the morning ramp time, however this is beyond the scope of this paper.

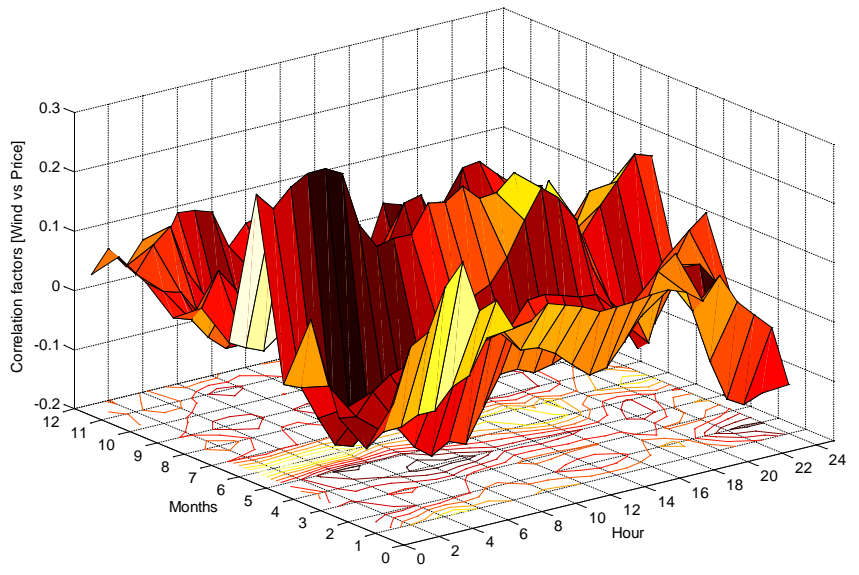

Fig. 12. Correlation of wind production share vs. price

\section{2) Correlation between RP and RES}

To determine the correlation between RP and RES production the same dataset was used as in Section VIII.E.1. Monthly RP instances were calculated with the KGB Model separately for peak- and off-peak periods.

Fig. 12 shows the results of correlation between PV production share and RP for the base- and peak periods. They show a negative correlation of $\mathrm{PV}$ and RP, except for the November positive correlation of 0.1695 in the off-peak period. June and July have the highest negative correlations, 0.73 and -0.76 , respectively.

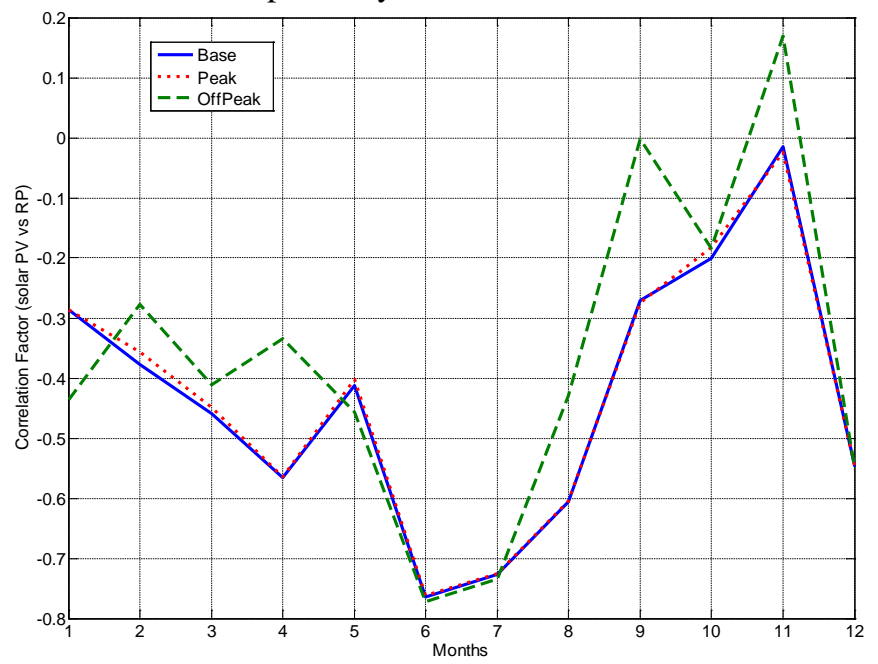

Fig. 13. Correlation of PV production share vs. RP

Wind production share and RP are negatively correlated for all months except for June, July, and August with positive correlations of $0.22,0.18$ and 0.05 , respectively, Fig. 13 . The correlation results for wind vs. RP are relevant, yet the correlation is weaker than that for PV vs. RP. October has the greatest negative correlation factor of -0.3 . 


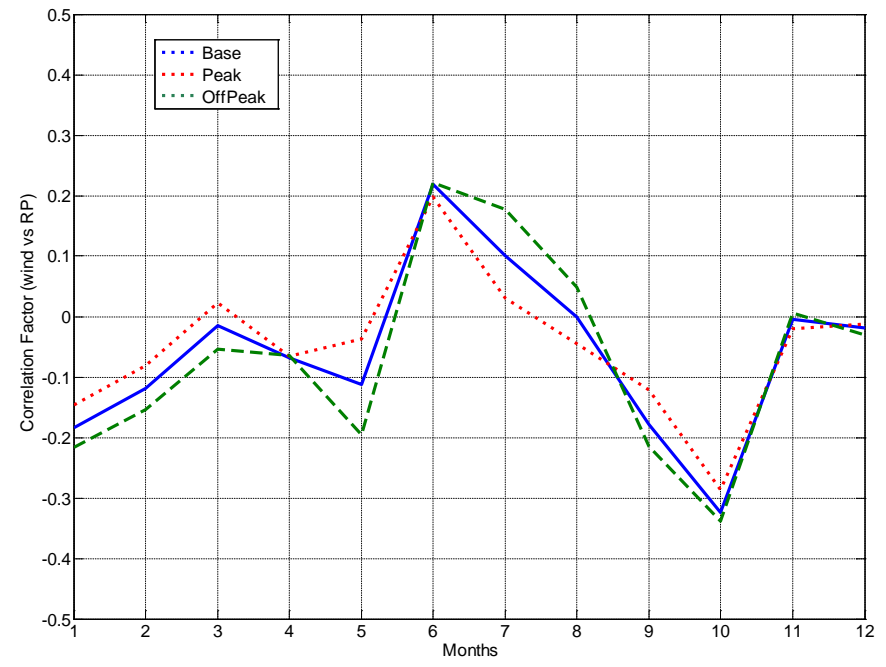

Fig. 14. Correlation of wind production share vs. RP

\section{F. KGB Linear Model Calibration using MLR}

To calculate the coefficients of the KGB Linear Model, MLR was used as expressed in (25). RP comes in two instances, peak and off-peak, expressed as $R_{P E A K}\left(t, T_{1}, T_{2}\right)$ and $R_{\text {off } P E A K}\left(t, T_{1}, T_{2}\right)$. The results of MLR show a significant dependence of RP on PV production share. According to (25), KGB Linear Model employs four variables, namely wind production share, PV production share, consumption, and time-to-maturity. The parameters of all four variables were obtained for both RP instances $R_{\text {PEAK }}\left(t, T_{1}, T_{2}\right)$ and $R_{\text {off_PEAK }}\left(t, T_{1}, T_{2}\right)$. The final results of MLR calculation with data on daily granularity (daily peak and daily off-peak for the annual product) are shown in TABLE II and TABLE III.

TABLE IV

\begin{tabular}{|c|c|c|c|c|c|c|}
\hline \multicolumn{2}{|c|}{$\begin{array}{l}\text { MULTIPLE LINEAR REGR } \\
\text { Regression Statistics PEAK }\end{array}$} & N Rt & LTS 1 & $1 \mathrm{H}$ & $P A$ & TANCE \\
\hline Multiple R & 0,961 & & & & & \\
\hline R Square & 0,923 & & & & & \\
\hline Adjusted R Square & 0,923 & & & & & \\
\hline Standard Error & 3,061 & & & & & \\
\hline Observations & 1461 & & & & & \\
\hline \multirow[t]{2}{*}{ ANOVA } & & & & & & \\
\hline & $d f$ & SS & $M S$ & & $\begin{array}{c}\text { Signif. } \\
F\end{array}$ & \\
\hline Regression & 4 & 164.627 & 41.157 & 4.392 & 0 & \\
\hline Residual & 1.456 & 13.645 & 9 & & & \\
\hline \multirow[t]{2}{*}{ Total } & 1.460 & 178.272 & & & & \\
\hline & Coefficients & \multicolumn{2}{|c|}{ Standard Error } & \multicolumn{2}{|c|}{$t$ Stat } & $P$-value \\
\hline Intercept & $-0,4270$ & \multicolumn{2}{|c|}{ 8,09E-01 } & \multicolumn{2}{|c|}{$2,88 \mathrm{E}+00$} & $3,98 \mathrm{E}-03$ \\
\hline Var. 1 - Wind prod. Share & $-1,03$ & \multicolumn{2}{|c|}{$1,09 \mathrm{E}+00$} & \multicolumn{2}{|c|}{$1,73 \mathrm{E}+00$} & 8,30E-02 \\
\hline Var. 2 - PV prod. Share & 17,03 & \multirow{2}{*}{\multicolumn{2}{|c|}{$\begin{array}{l}1,27 \mathrm{E}+00 \\
9,07 \mathrm{E}-07\end{array}$}} & \multicolumn{2}{|c|}{$-3,53 E+00$} & $4,27 \mathrm{E}-04$ \\
\hline Var. 3 - Consum. & $6,18 \mathrm{E}-06$ & & & \multirow{2}{*}{\multicolumn{2}{|c|}{$\begin{array}{c}-6,95 \mathrm{E}-01 \\
1,25 \mathrm{E}+02\end{array}$}} & $4,87 \mathrm{E}-01$ \\
\hline \multirow[t]{2}{*}{ Var. 4 - Time interc. } & 0,0104 & \multicolumn{2}{|c|}{$2,00 \mathrm{E}-04$} & & & $0,00 \mathrm{E}+00$ \\
\hline & Lower 95\% & \multicolumn{2}{|c|}{ Upper 95\% } & \multicolumn{2}{|c|}{ Lower $95,0 \%$} & Upper 95,0\% \\
\hline $\begin{array}{l}\text { Intercept } \\
\end{array}$ & $7,47 \mathrm{E}-01$ & \multicolumn{2}{|c|}{$3,92 \mathrm{E}+00$} & \multicolumn{2}{|c|}{$7,47 \mathrm{E}-01$} & $3,92 \mathrm{E}+00$ \\
\hline Var. 1-Wind prod. Share & $-2,47 \mathrm{E}-01$ & \multirow{2}{*}{\multicolumn{2}{|c|}{$\begin{array}{r}4,02 \mathrm{E}+00 \\
-1,99 \mathrm{E}+00\end{array}$}} & \multicolumn{2}{|c|}{$-2,47 \mathrm{E}-01$} & $4,02 E+00$ \\
\hline Var. 2 - PV prod. Share & $-6,96 \mathrm{E}+00$ & & & \multicolumn{2}{|c|}{$-6,96 E+00$} & $-1,99 \mathrm{E}+00$ \\
\hline Var. 3 - Consum. & $-2,41 \mathrm{E}-06$ & \multirow{2}{*}{\multicolumn{2}{|c|}{ 1,15E-06 }} & \multicolumn{2}{|c|}{$-2,41 \mathrm{E}-06$} & $1,15 \mathrm{E}-06$ \\
\hline Var. 4 - Time interc. & $2,46 \mathrm{E}-02$ & & & \multicolumn{2}{|c|}{$2,46 \mathrm{E}-02$} & $2,54 \mathrm{E}-02$ \\
\hline
\end{tabular}

The MLR results for the peak period in TABLE I show that the three variables (PV, consumption, and time-to-maturity) are relevant because P-value in these three cases is far below 0.05. An exception is the fourth independent variable, wind production share, with $\mathrm{P}$-value $\mathrm{p}=0.0830$, that is not significant enough to determine the dependent variable $\mathrm{R}_{P E A K}\left(t, T_{1}, T_{2}\right)$.

The overall significance of MLR is confirmed having significance $\mathrm{F}<0.05$. Adjusted $\mathrm{R}$ square confirms that $92.3249 \%$ of the dependent variable RP has been described by those four variables.

The results of MLR for the off-peak period in TABLE III show that the $\mathrm{P}$-value for all three variables is below $\mathrm{P}<0.05$ and therefore they are relevant. The overall significance of the off-peak period MLR is confirmed as well. The adjusted R square confirms that $92.5775 \%$ of dependent variable RP is described by those four variables. The peak- vs. off-peak period observation reveals the true impact of RES on electricity price and on RP.

The MLR results of KGB Linear Model coefficients show that during peak hours wind production share coefficient is negative (-1.03), decreasing the $\mathrm{R}_{P E A K}\left(t, T_{1}, T_{2}\right)$, where $\mathrm{PV}$ production share coefficient is positive $(+17.03)$, increasing $\mathrm{R}_{P E A K}\left(t, T_{1}, T_{2}\right)$. During the of off-peak period, wind production share coefficient has positive sign (0.49) therefore increasing the $\mathrm{R}_{\text {off_PEAK }}\left(t, T_{1}, T_{2}\right)$, where $\mathrm{PV}$ production share coefficient is negative (-16.53), decreasing $\mathrm{R}_{\text {off_PEAK }}\left(t, T_{1}, T_{2}\right)$.

TABLE V

MULTIPLE LINEAR REGRESSION RESULTS FOR THE OFF-PEAK PERIOD Regression Statistics Off-PEAK

\begin{tabular}{lr}
\hline Multiple R & 0,962 \\
R Square & 0,926 \\
Adjusted R Square & 0,926 \\
Standard Error & 2,302 \\
Observations & 1461 \\
\hline
\end{tabular}

\begin{tabular}{|c|c|c|c|c|c|c|}
\hline \multicolumn{6}{|l|}{ ANOVA } & \\
\hline & $d f$ & SS & MS & $F$ & $\begin{array}{c}\text { Signif. } \\
F\end{array}$ & \\
\hline Regression & 4 & 96.487 & 24.122 & 4.554 & 0 & \\
\hline Residual & 1.456 & 7.713 & 5 & & & \\
\hline \multirow[t]{2}{*}{ Total } & 1.460 & 104.200 & & & & \\
\hline & Coefficients & \multicolumn{2}{|c|}{ Standard Error } & \multicolumn{2}{|c|}{$t$ Stat } & $P$-value \\
\hline Intercept & 0,8312 & \multicolumn{2}{|c|}{ 6,37E-01 } & \multicolumn{2}{|c|}{$-4,08 E+00$} & $4,79 \mathrm{E}-05$ \\
\hline Var. 1 - Wind prod. Share & 0,49 & \multicolumn{2}{|c|}{ 7,34E-01 } & \multicolumn{2}{|c|}{$1,69 \mathrm{E}+00$} & $9,20 \mathrm{E}-02$ \\
\hline Var. 2 - PV prod. Share & $-16,53$ & \multicolumn{2}{|c|}{$1,78 \mathrm{E}+01$} & \multicolumn{2}{|c|}{$-6,29 E+00$} & $4,24 \mathrm{E}-10$ \\
\hline Var. 3 - Consum. & $-1,20 \mathrm{E}-06$ & \multicolumn{2}{|c|}{$9,78 \mathrm{E}-07$} & \multicolumn{2}{|c|}{$-2,37 E+00$} & 1,77E-02 \\
\hline \multirow[t]{2}{*}{ Var. 4 - Time interc. } & 0,0016 & \multicolumn{2}{|c|}{$1,47 \mathrm{E}-04$} & \multicolumn{2}{|c|}{$1,30 \mathrm{E}+02$} & $0,00 \mathrm{E}+00$ \\
\hline & Lower 95\% & \multicolumn{2}{|c|}{ Upper 95\% } & \multicolumn{2}{|c|}{ Lower 95,0\% } & Upper $95,0 \%$ \\
\hline Intercept & $-3,8447$ & \multicolumn{2}{|c|}{$-1,35 \mathrm{E}+00$} & \multicolumn{2}{|c|}{$-3,84 \mathrm{E}+00$} & $-1,35 \mathrm{E}+00$ \\
\hline Var. 1 - Wind prod. Share & $-2,02 \mathrm{E}-01$ & \multicolumn{2}{|c|}{$2,68 \mathrm{E}+00$} & \multicolumn{2}{|c|}{$-2,02 \mathrm{E}-01$} & $2,68 \mathrm{E}+00$ \\
\hline Var. 2 - PV prod. Share & $-1,47 E+02$ & \multicolumn{2}{|c|}{$-7,69 \mathrm{E}+01$} & \multicolumn{2}{|c|}{$-1,47 \mathrm{E}+02$} & $-7,69 \mathrm{E}+01$ \\
\hline Var. 3 - Consum. & $-4,24 \mathrm{E}-06$ & \multicolumn{2}{|c|}{$-4,04 \mathrm{E}-07$} & \multicolumn{2}{|c|}{$-4,24 \mathrm{E}-06$} & $-4,04 \mathrm{E}-07$ \\
\hline Var. 4 - Time interc. & 1,88E-02 & \multicolumn{2}{|c|}{ 1,94E-02 } & \multicolumn{2}{|c|}{$1,88 \mathrm{E}-02$} & $1,94 \mathrm{E}-02$ \\
\hline
\end{tabular}

The coefficients show that RP is increasing with the wind production share during the off-peak period and with the PV production share during the peak period, where the impact of $\mathrm{PV}$ is 35.3 times greater. On the other hand, RP is decreased by the wind during the peak period and by the PV during the off-peak period, where the impact of PV is 16.53 times greater. The results for the observation period of $2010-2014$ reveal that the overall influence of PV production share on RP 
is greater than the wind production share, yet both are relevant and contribute to RP determination. Further economic insights into the reasons for RP behavior would require extensive additional analyses that are beyond the scope of this paper. However, the tools proposed in this paper, the KGB Method and the associated models, facilitate further such analyses.

\section{G. KGB Linear Model Use}

Based on the results from MLR in both instances (peak and off-peak for the annual product), the market participants can forecast RP with a limited set of input data using KGB Linear Model. To forecast RP on Sept $30^{\text {th }}$, 2015 for the next 10 consecutive days ahead, a market participant only needs an estimated mean value of wind production share, PV production share, and consumption for the chosen period of 10 days ahead. Considering that an active market participant daily operates with those data, simulation of mean RP value should be rather straightforward using (25), with 10 values of $\mathrm{RP}$ for each instance. The required coefficients $\left(A_{1}, A_{2}, A_{3}\right.$ and $A_{4}$ ), and the intercept $A_{0}$ are listed in TABLE II and TABLE III, To simulate deviation from expected mean, the respective values of the lower and upper confidence interval were used, and the results of the Monte Carlo simulation are shown in TABLE IV and in Fig. 14. In the figure, the calculated values of RP via the KGB Model are followed by the 10-day KGB Linear Model forecasted RP values (in blue) with the associated confidence intervals (dashed lines), for the two respective instances.

TABLE VI

RESULTS OF KGB LINEAR MODEL FORECAST FOR ANNUAL

\begin{tabular}{|c|c|ccc|ccc|}
\hline \multirow{5}{*}{$\begin{array}{c}\text { Time } \\
\text { Frame }\end{array}$} & \multicolumn{2}{|c|}{$\begin{array}{c}\text { RP PEAK [EUR/MWh] } \\
\text { bound }\end{array}$} & Mean FC & $\begin{array}{c}\text { Upper } \\
\text { bound }\end{array}$ & $\begin{array}{c}\text { Lower } \\
\text { bound }\end{array}$ & Mean FC & $\begin{array}{c}\text { Upper } \\
\text { bound }\end{array}$ \\
\cline { 2 - 8 } Risk Premium & 1 & 4,55237 & 7,41377 & 8,63256 & 0,15347 & 0,42925 & 0,88496 \\
FORECAST & 2 & 5,02629 & 7,79047 & 9,12385 & 0,12567 & 0,37496 & 0,76423 \\
& 3 & 4,93796 & 7,20967 & 9,35749 & 0,11203 & 0,31111 & 0,71819 \\
& 4 & 5,04116 & 7,91776 & 10,45436 & 0,09727 & 0,26327 & 0,56114 \\
& 5 & 5,05712 & 8,57304 & 10,66486 & 0,08624 & 0,27340 & 0,57389 \\
& 6 & 5,84578 & 9,19814 & 11,55613 & 0,12085 & 0,26158 & 0,62644 \\
& 7 & 5,94203 & 8,93716 & 10,41439 & 0,16237 & 0,35387 & 0,71281 \\
& 8 & 5,11249 & 7,74840 & 10,41479 & 0,21243 & 0,48983 & 1,07844 \\
& 9 & 3,95541 & 7,01167 & 8,73008 & 0,13764 & 0,38879 & 0,87312 \\
& 10 & 4,02636 & 7,62055 & 10,23932 & 0,09803 & 0,32404 & 0,76078 \\
\hline
\end{tabular}
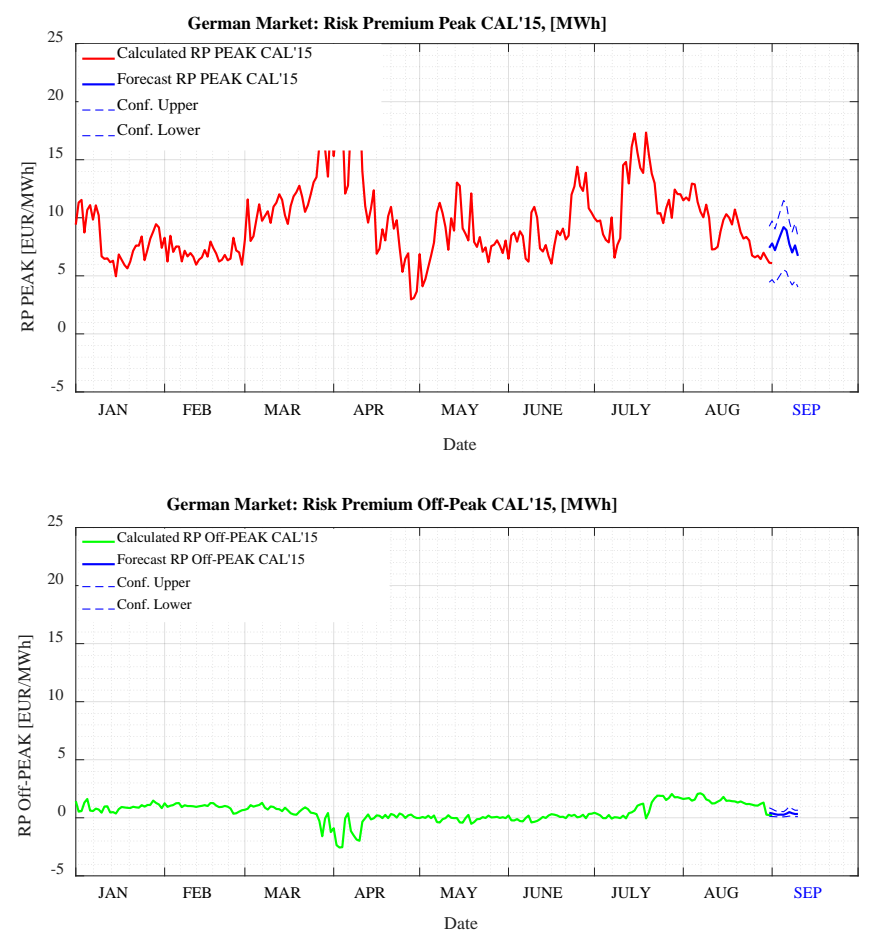

Fig. 15: KGB Linear Model forecast for peak and off-peak instances

The market actors could use the KGB Linear Model forecast results in various areas, e.g. risk management and trading. In the risk management, prospective energy companies would be focused on MC simulation results to quantify the value of possible loss in the worst-case scenario, [38].

Traders, producers and suppliers would act according to their current portfolio position (having a short or long position) and would use such a result to optimize their trading strategies. Based on the results of RP forecasts market actors would be able to accelerate or delay any trade to obtain a positive difference. When a producer needs to sell the next tranche of production on annual basis, and the 10-day RP peak annual product forecast as shown in TABLE IV indicates significantly higher values (e.g. $11.56 \mathrm{EUR} / \mathrm{MWh}$ ) than observed today (e.g. 7.41 EUR/MWh), the producer could delay such a trade, according to the corporate risk tolerance. With the smallest tranche on EEX Derivatives equaling to 1 LOT (5 MW - equaling to $15,600 \mathrm{MWh}$ p.a.) and the producer deciding to delay the transaction at the target $\mathrm{RP}=$ 10 EUR/MWh, the payoff of such delay could yield a profit of 40,404 EUR. From the experience, typical tranches of a midsize producer equal to $50 \mathrm{MW}$ of annual products, yielding considerable profits without significantly increasing the risk exposure.

\section{CONCLUSION}

The main purpose of this paper was to propose a new stochastic KGB Model for RP calculation and the associated KGB Method for its use based on the "ex-ante" calculation approach that would allow for risk premium forecast of a 
year-ahead electricity products in the German power market with the use of a limited set of input data. Our aim was to capture the intraday dynamics of RP driven by RES production.

In the initial calculation, RP exhibits a time-varying and extremely volatile character. To facilitate its use, the RP model is expressed in a linear form as the KGB Linear Model (25), with MLR used for its calibration. It was very important to define the right exogenous variables to provide enough explanatory power, as expressed by adjusted $\mathrm{R}$ square. For this purpose, pairwise cross-correlations separately with price and with RP were performed with different independent variables (wind- and PV production share in generation mix in particular) to determine their behavior and their impact on both, price and RP. Empirical observations show that where PV production share has displayed the greatest positive impact on RP during the peak hours, wind production share did so during the off-peak hours. However, the exact wind production share contribution to price and RP, e.g. during the morning ramp, cannot be readily determined without the comprehensive analysis of price drivers which is beyond the scope of this paper. It can be assumed that the high dynamics of conventional generation present in the morning ramp part of the off-peak consumption can mask the true contribution of variable RES, especially wind.

The MLR results for both instances confirm the overall significance of the KGB Linear Model. The significance of $\mathrm{PV}$ production share in the off-peak instance was surprising because the off-peak period is usually associated with night hours without sunshine. However, the dynamics in PV production in the morning yet off-peak hours from 05:00 to 08:00 during the morning ramp in electricity consumption obviously makes a significant enough contribution of PV production mix to drive the overall PV off-peak significance.

The results show that the variable RES production plays a key role in price determination, which is in general negatively correlated to RES production due to its low marginal cost. However, the instances of positive correlation of RES to RP can arise during other periods, so the connection cannot simply be expressed with a positive or a negative correlation as it very much depends on the share of RES production in the total electricity production mix.

There are many opportunities arising from the use of the proposed RP models in RP forecasting. The proposed KGB Method simplifies the computation of RP, especially with the KGB Linear Model that is aimed at a broader audience of market actors beyond the specialized analytics departments of large energy traders. Their use could be expanded to all future products from weekly products to yearly products for a few years in advance.

The KGB Method allows the insight into significant market changes due to variable RES impact (in particular wind and $\mathrm{PV}$ production). The impact is already visible from the RP results in years 2010 to 2014. With further intensive growth of RES share in total production mix during the period 20152019 and beyond, we strongly believe that the influence of RES will become a key driver of RP.

\section{REFERENCES}

[1] R. S. Pindyck, 'The Long-Run Evolutions of Energy Prices', Energy J., vol. 20, no. 2, pp. 1-27, 1999.

[2] R. Huisman and M. Kilic, 'Electricity Futures Prices: Indirect Storability, Expectations, and Risk Premiums', Energy Econ., vol. 34, no. 4, pp. 892-898, 2012.

[3] M. Povh and S. E. Fleten, 'Modeling long-term electricity forward prices', IEEE Trans. Power Syst., vol. 24, no. 4, pp. 1649-1656, 2009.

[4] R. Weron, 'Market price of risk implied by Asian-style electricity options and futures', Energy Econ., vol. 30, no. 3, pp. 1098-1115, 2008.

[5] D. W. Bunn and D. Chen, 'The forward premium in electricity futures', J. Empir. Financ., vol. 23, pp. 173-186, 2013.

[6] J. J. Lucia and H. Torró, 'On the risk premium in Nordic electricity futures prices', Int. Rev. Econ. Financ., vol. 20, no. 4, pp. 750-763, 2011.

[7] A. Botterud, T. Kristiansen, and M. D. Ilic, 'The relationship between spot and futures prices in the Nord Pool electricity market', Energy Econ., vol. 32, no. 5, pp. 967-978, Sep. 2010.

[8] D. Furió and V. Meneu, 'Expectations and forward risk premium in the Spanish deregulated power market’, Energy Policy, vol. 38, no. 2, pp. 784-793, 2010.

[9] F. E. Benth, Á. Cartea, and R. Kiesel, 'Pricing forward contracts in power markets by the certainty equivalence principle: Explaining the sign of the market risk premium', J. Bank. Financ., vol. 32, no. 10, pp. 2006-2021, 2008.

[10] P. Skantze, M. Ilic, and A. Gubina, 'Modelling locational price spreads in competitive electricity markets; applications for transmission rights valuation and replication', IMA J. Manag. Math., vol. 15, no. 4, pp. 291-319, 2004.

[11] C. Pirrong and M. Jermakyan, 'The price of power: The valuation of power and weather derivatives', J. Bank. Financ., vol. 32, no. 12, pp. 2520-2529, Dec. 2008.

[12] J. Viehmann, 'Risk premiums in the German day-ahead Electricity Market', Energy Policy, vol. 39, no. 1, pp. 386-394, 2011.

[13] M. Pietz, 'Risk premia in the German electricity futures market. CEFS working paper series, No. 2009-07', in ICEE 2009 3rd International Conference on Energy and Environment, 2009, no. May, pp. 160-170.

[14] Wind and power 2017, 'Wind and power 2017: Annual combined onshore and offshore wind energy statistics', 2018.

[15] E. E. Agency, '1. Overall progress towards the European Union's “2020-20" climate and energy targets', European Environmental Agency, $2018 . \quad$ [Online]. Available: https://www.eea.europa.eu/themes/climate/trends-and-projections-ineurope/trends-and-projections-in-europe-2017/overall-progresstowards-the-european\#1-1-progress-of-the-european-union-towardsits--20-20-20--climate-and-energy-targets.

[16] F. E. Benth, J. Šaltyte-Benth, and S. Koekebakker, Stochastic Modeling Of Electricity And Related Markets, vol. 11. 2008.

[17] A. Escribano, J. Ignacio Peña, and P. Villaplana, 'Modelling electricity prices: International evidence', Oxf. Bull. Econ. Stat., vol. 73, no. 5, pp. 622-650, 2011.

[18] A. B. Trolle and E. S. Schwartz, 'Unspanned stochastic volatility and the pricing of commodity derivatives', Rev. Financ. Stud., vol. 22, no. 11, pp. 4423-4461, 2009.

[19] E. Schwartz and J. E. Smith, 'Short-Term Variations and Long-Term Dynamics in Commodity Prices’, Manage. Sci., vol. 46, no. 7, pp. 893911, 2003.

[20] F. E. Benth, R. Kiesel, and A. Nazarova, 'A critical empirical study of three electricity spot price models', Energy Econ., vol. 34, no. 5, pp. 1589-1616, 2012.

[21] J. C. Hull, Options, Futures, and Other Derivatives, 8. Toronto: Prentice Hall, Pearson Education, Inc., 2012.

[22] B. Oksendal, Stochastic Differential Equations: An Introduction with Applications., Fifth Edit., vol. 82, no. 399. Springer Science \& Business Media, 2006.

[23] F. E. Benth and S. Ortiz-Latorre, 'A pricing measure to explain the risk premium in power markets', SIAM J. Finan. Math., vol. 5, no. 1, pp. 685-728, 2014.

[24] J. Mauritzen, 'What Happens When it's Windy in Denmark? An Empirical Analysis of Wind Power on Price Variability in the Nordic Electricity Market’, Ssrn, no. December, 2012. 
[25] J. C. Ketterer, 'The impact of wind power generation on the electricity price in Germany', Energy Econ., vol. 44, pp. 270-280, 2014.

[26] T. Rintamäki, A. S. Siddiqui, and A. Salo, 'Does renewable energy generation decrease the volatility of electricity prices? An analysis of Denmark and Germany', Energy Econ., vol. 62, pp. 270-282, 2017.

[27] R. H. Shumway and D. S. Stoffer, Time series analysis and its application, 3., vol. 22, no. 4. 2008.

[28] Economic Consulting Associates Limited, 'European Electricity Forward Markets and Hedging Products - State of Play and Elements for Monitoring Final Report', Eur. Electr. Forw. Mark. Hedging Prod. - State Play Elem. Monit. Final Rep., vol. 4, pp. 1-204, 2015.

[29] EEX Derivatives, 'EEX Market product information: Phelix-DE Futures', 2019. [Online]. Available: https://www.eex.com/en/products/power-derivatives-market/powerfutures/power-futures-products.

[30] EPEX Spot, 'Market information: Extras Download', 2019. [Online]. Available: https://www.epexspot.com/en/extras/download-center.

[31] EEX Market product inf., 'EEX Market product information: PhelixDE Futures', 2019. [Online]. Available: https://www.eex.com/en/products/power-derivatives-market/phelix-defutures.

[32] European Commodity Clearing AG, 'Clearing house information: Product Specification Files’, 2019. [Online]. Available: http://www.ecc.de/ecc-en/.

[33] EPEX Spot, 'EPEX Spot Market Data: Day-Ahead Auction', 2019. [Online]. Available: https://www.epexspot.com/en/market-data/.

[34] EEX Market Data, 'EEX Market Data: Phelix-DE Futures', 2019. [Online]. Available: https://www.eex.com/en/marketdata/power/futures/phelix-de-futures\#!/2018/11/13.

[35] ENTSO-E Transparency Platform, 'Historical data (until December 2015)', 2016. [Online]. Available: https://www.entsoe.eu/data/dataportal/.

[36] ENTSO-E Transparency Platform, 'Actual Generation per Production Type’, ENTSO-E Transparency Platform, 2017. [Online]. Available: https://transparency.entsoe.eu.

[37] Potomac Economics, '2017 State of the Markert Report for the ERCOT Electricity Markets', 2018.

[38] N. Krečar and A. F. Gubina, 'Risk Mitigation in the New Renewable Energy Sources Environment', Accepted in WIREs Energy Environ., no. manuscript no. WENE-679, DOI: 10.1002/wene.362, 2019.

Nikola Krečar (M’18) received his Master of Science from the Faculty of Electrical Engineering, University of Ljubljana in 2010. During 2009-2010, he was a Head of the trading department in the electricity-distribution company, Elektro Ljubljana d.d., during 2011 - 2014 Executive Director of Wholesale trading in Elektro energija d.o.o., during 2015 - 2018 appointed to position of Managing Director of RWE Ljubljana d.o.o. and during the same period to a position of Advisor to BoD of RWE Hrvatska d.o.o. His areas of interest include electricity markets, trading, risk management, structural deals and portfolio analyses.

Fred Espen Benth is professor of mathematical finance at the University of Oslo. In 1995 he defended his $\mathrm{PhD}$ in applied mathematics at the same institution, and thereafter worked at the Norwegian Computing Center for three years as a statistical consultant for the oil industry. He has spent one year as a research assistant at the University of Mannheim, Germany, and one year as a post doc at the University of Aarhus, Denmark. His research interests are on mathematical finance and stochastic analysis, with special focus to applications in energy markets. Benth has published more than 90 papers in international journals, and is the author of one introductory book on mathematical finance, and co-author of two research monographs on energy and weather markets. He is actively involved in consultancy and teaching for the energy industry.

Andrej F. Gubina (M’95, SM'15) received his Ph.D. degree in Electrical Engineering from University of Ljubljana, Slovenia in 2002. During 20002001 he was a Fulbright Visiting Scholar at the Energy Laboratory, Massachusetts Institute of Technology. He is currently an Associate Professor and the Head of Energy Policy Laboratory at the University of Ljubljana, Faculty of Electrical Engineering. His field of research encompasses Power System Economics and Deregulation, Production Planning under Open Electricity Market Conditions, Risk Management and Asset Management in EPS, Demand Side Management, Energy Efficiency of Demand and Renewable Energy Sources integration in power system. He is a guest lecturer on RES integration and policy design in Europe, and a holder of technology patents. He is a Senior Member of IEEE PES and Member of CIGRE Paris. 